\title{
Application of the Direct Strength Method to local buckling resistance of thin-walled steel members with non-uniform elevated temperatures under axial compression
}

\author{
Ashkan Shahbazian, Yong Chang Wang* \\ School of Mechanical, Aerospace and Civil Engineering, the University of Manchester, Pariser Building, Sackville Street, Manchester M13 9PL, United Kingdom
}

\section{A R T I C L E I N F O}

\section{Article history:}

Received 21 July 2011

Received in revised form

5 August 2011

Accepted 9 August 2011

Available online 25 August 2011

\section{Keywords:}

Steel

Cold-formed

Thin-walled

Direct Strength Method

Local buckling

Fire resistance

Numerical modelling

Non-uniform elevated temperature

\begin{abstract}
A B S T R A C T
This paper assesses the applicability of the Direct Strength Method (DSM) to calculating the local buckling ultimate strength of cold-formed thin-walled (CF-TW) steel members with non-uniform elevated temperature distributions in the cross-section. The assessment was carried out by checking the DSM calculation results with numerical simulation results using the general finite element software ABAQUS which was validated against ambient and uniform elevated temperature tests on short lipped channel sections. The validated numerical model was used to generate an extensive database ( 372 models) of numerical results of load carry capacity of CF-TW members with different uniform and nonuniform temperature distributions in the cross-sections, under different boundary and loading conditions and with different dimensions and lengths. It was concluded that the DSM local buckling curve was directly applicable for columns with uniform temperature distributions in the cross-section. For columns with non-uniform temperature distributions, a modification to the local buckling curve was necessary and this paper has proposed a new curve.
\end{abstract}

(c) 2011 Elsevier Ltd. All rights reserved.

\section{Introduction}

To calculate the load carrying capacity of cold-formed thinwalled (CF-TW) structural members, the effective width method has traditionally been followed. Although the effective width method is still widely used, the Direct Strength Method (DSM) [1] is becoming more popular because it avoids lengthy calculations for effective widths, which is useful for sections with multi-stiffeners. For CF-TW members exposed to fire condition, calculating the effective widths of a cross-section can become tedious because the cross-section will have non-uniform distribution of mechanical properties due to the steel plates having nonuniform temperature distributions. Under this circumstance, using DSM would be particularly advantageous.

DSM is an extension of the concept of column buckling curve for global buckling to the other two buckling modes of thinwalled members: local and distortional buckling. The crosssectional plastic resistance and the elastic global buckling load are required when calculating the global buckling resistance of the column. Similarly, additional quantities of the elastic local and

\footnotetext{
*Corresponding author. Tel.: +441613068968.

E-mail address: yong.wang@manchester.ac.uk (Y.Chan. Wang).
}

distortional critical buckling loads should be provided when using DSM to calculate the local and distortional buckling resistance of the column. For a column, the DSM procedure is implemented in the following way [2]:

- Global buckling (flexural, torsional or flexural-torsional)

$$
\begin{aligned}
& \lambda_{c}=\sqrt{\frac{P_{y}}{P_{c r e}}} \\
& \text { for } \lambda_{c} \leq 1.5 \quad P_{n e}=\left(0.658^{\lambda_{c}^{2}}\right) P_{y} \\
& \text { for } \lambda_{c}>1.5 \quad P_{n e}=\left(\frac{0.877}{\lambda_{c}^{2}}\right) P_{y}
\end{aligned}
$$

- Distortional buckling

$$
\begin{aligned}
& \lambda_{d}=\sqrt{\frac{P_{y}}{P_{c r d}}} \\
& \text { for } \lambda_{d} \leq 0.561 \quad P_{n d}=P_{y} \\
& \text { for } \lambda_{d}>0.561 \quad P_{n d}=\left(1-0.25\left(\frac{P_{c r d}}{P_{y}}\right)^{0.6}\right)\left(\frac{P_{c r d}}{P_{y}}\right)^{0.6} P_{y}
\end{aligned}
$$




\title{
Application of the Direct Strength Method to Local Buckling Resistance of Thin-Walled Steel
}

\author{
Members with Non-Uniform Elevated Temperatures under Axial Compression
}

\section{Ashkan Shahbazian, Yong Chang Wang*}

School of Mechanical, Aerospace and Civil Engineering, the University of Manchester, United Kingdom

*corresponding author

Email:yong.wang@manchester.ac.uk

Address: School of Mechanical, Aerospace and Civil Engineering, the University of Manchester, Pariser Building, Sackville Street, Manchester M13 9PL, United Kingdom

Tel: 00441613068968

\begin{abstract}
This paper assesses the applicability of the Direct Strength Method (DSM) to calculating the local buckling ultimate strength of cold-formed thin-walled (CF-TW) steel members with non-uniform elevated temperature distributions in the cross-section. The assessment was carried out by checking the DSM calculation results with numerical simulation results using the general finite element software ABAQUS which was validated against ambient and uniform elevated temperature tests on short lipped channel sections. The validated numerical model was used to generate an extensive database (372 models) of numerical results of load carry capacity of CF-TW members with different uniform and non-uniform temperature distributions in the cross-sections, under different boundary and loading conditions and with different dimensions and lengths. It was concluded that the DSM local buckling curve was directly applicable for columns with uniform temperature distributions in the cross-section. For columns with non-uniform temperature distributions, a modification to the local buckling curve was necessary and this paper has proposed a new curve.
\end{abstract}

Keywords: Steel; Cold-formed; Thin-walled; Direct Strength Method; Local Buckling; Fire Resistance; Numerical Modelling; Non-Uniform Elevated Temperature; 


\section{Introduction}

To calculate the load carrying capacity of cold-formed thin-walled (CF-TW) structural members, the effective width method has traditionally been followed. Although the effective width method is still widely used, the Direct Strength Method (DSM) [1] is becoming more popular because it avoids lengthy calculations for effective widths, which is useful for sections with multi stiffeners. For CF-TW members exposed to fire condition, calculating the effective widths of a cross-section can become tedious because the cross-section will have non-uniform distribution of mechanical properties due to the steel plates having non-uniform temperature distributions. Under this circumstance, using DSM would be particularly advantageous.

DSM is an extension of the concept of column buckling curve for global buckling to the other two buckling modes of thin-walled members: local and distortional buckling. The cross-sectional plastic resistance and the elastic global buckling load are required when calculating the global buckling resistance of the column. Similarly, additional quantities of the elastic local and distortional critical buckling loads should be provided when using DSM to calculate the local and distortional buckling resistance of the column. For a column, the DSM procedure is implemented in the following way [2]:

- Global Buckling (flexural, torsional or flexural-torsional):

$$
\begin{gathered}
\lambda_{c}=\sqrt{\frac{P_{y}}{P_{\text {cre }}}} \\
\text { for } \lambda_{c} \leq 1.5 \\
\text { for } \lambda_{c}>1.5
\end{gathered} \quad \begin{aligned}
& P_{n e}=\left(0.658^{\lambda_{c}{ }^{2}}\right) P_{y} \\
& P_{n e}=\left(\frac{0.877}{\lambda_{c}{ }^{2}}\right) P_{y}
\end{aligned}
$$

- Distortional Buckling:

$$
\begin{gathered}
\lambda_{d}=\sqrt{\frac{P_{y}}{P_{c r d}}} \\
P_{n d}=P_{y} \\
\text { for } \lambda_{d} \leq 0.561 \\
\text { for } \lambda_{d}>0.561 \quad P_{n d}=\left(1-0.25\left(\frac{P_{c r d}}{P_{y}}\right)^{0.6}\right)\left(\frac{P_{c r d}}{P_{y}}\right)^{0.6} P_{y}
\end{gathered}
$$

- Local Buckling:

for $\lambda_{l} \leq 0.776$

$$
\lambda_{l}=\sqrt{\frac{P_{n e}}{P_{c r l}}}
$$




$$
\text { for } \lambda_{l}>0.776 \quad P_{n l}=\left(1-0.15\left(\frac{P_{c r l}}{P_{n e}}\right)^{0.4}\right)\left(\frac{P_{c r l}}{P_{n e}}\right)^{0.4} P_{n e}
$$

In the above equations:

$P_{y}$ is the squash load of the cross-section;

$P_{c r e}$ is the critical elastic global buckling load;

$P_{c r d}$ is the critical elastic distortional buckling load;

$P_{c r l}$ is the critical elastic local buckling load;

$\lambda_{c}, \lambda_{d}$ and $\lambda_{l}$ are slenderness for global, distortional and local buckling modes respectively;

$P_{n e}, P_{n l}$ and $P_{n d}$ are the nominal axial strength for global, distortional and local buckling modes respectively.

In a recent study by the authors [3], a new methodology was developed to calculate the cross-section squash load and elastic critical global buckling load for columns with non-uniform temperature distributions. In the same study, a modified global buckling curve was proposed (Figure 1) to replace equations 2 and 3 to account for non-uniform temperature distributions in the cross-section when calculating the column strength under global buckling mode. This was necessary to allow for the additional effects of temperature gradients in the cross-section such as thermal stress. The modified equations are:

$$
\begin{array}{ll}
\text { for } \lambda_{c} \leq 1.5 & P_{n e}=\left(0.495^{\lambda_{c}{ }^{2}}\right) P_{y} \\
\text { for } \lambda_{c}>1.5 & P_{n e}=\left(\frac{0.462}{\lambda_{c}{ }^{2}}\right) P_{y}
\end{array}
$$




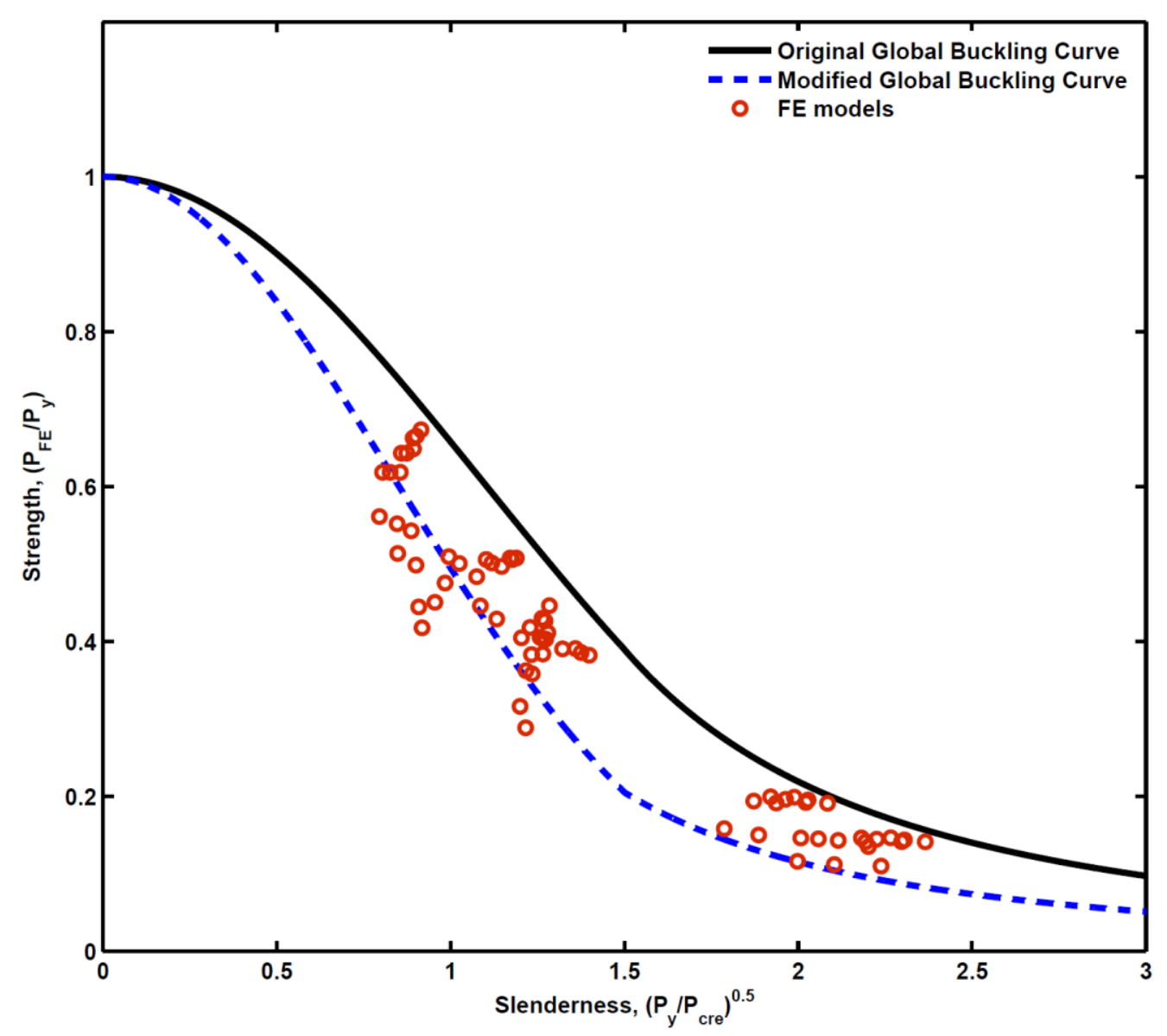

Figure 1. Comparing FE Simulation Results with Original Global and Modified Global Buckling Curve [3]

This paper will focus on the local buckling mode and will assess the accuracy of equations 8 and 9 .

To accompany the use of DSM, Schafer et al. [4] has developed the freely available Finite Strip software CUFSM to calculate the three elastic critical buckling loads. For ambient temperature application, the squash load of the cross-section is simply the cross-sectional area multiplied by the yield stress of steel. Elevated temperatures in the cross-section of a thin-walled member will change the material properties. In particular, the non-uniform temperature distributions in the cross-section will require modifications when calculating the elastic critical buckling loads and the cross-sectional squash load. This will be explained in section 5.

For ambient temperature applications, DSM has been adopted in AISI [2] and is known as the Appendix 1 method. A large number of research studies have been carried out to develop this method and an extensive review has been provided by Schafer [5].

There have been very few studies to investigate the behaviour of CF-TW structures exposed to fire. The investigations of Feng et al. [6-13] represent the most thorough study in this field. They carried out elevated temperature and fire tests on CF-TW members and panels, and numerical and analytical studies to quantify heat transfer and load carrying capacities. Their experiments on short CF-TW columns $[8,11]$ 
will be used in this research to validate the numerical model using ABAQUS [14] and their heat transfer results $[6,7]$ will be adopted in this study to determine the assumed temperature distributions.

Research studies to explore DSM for elevated temperature applications are rare. The investigation by Heva et al. [15] concluded that DSM would be suitable for local buckling, but their study was limited to uniform temperature distribution in the cross-section and did not consider the interaction between local and global buckling.

For distortional buckling, a preliminary study was carried out by Ranawaka et al. [16] for members with uniform temperature. They compared the DSM distortional buckling results with both numerical and experimental results and concluded that in many cases the DSM distortional buckling curve would give un-conservative results but in some cases the results were conservative. Landesmann et al. [17] modified the DSM distortional buckling curve based on temperature. Again this study was for uniform temperature distribution only.

This paper will assess the applicability of DSM to local buckling, specifically the accuracy of equations 8 and 9. This research will be carried out by comparisons of the DSM calculation results with numerical simulation results using the general Finite Element package ABAQUS [14]. Validation of the ABAQUS model may be established by checking numerical simulation results against the experimental results of Feng et al. [11] on short columns that experienced local buckling at elevated temperatures. 


\section{Calculation of Elastic Buckling Loads}

To calculate the various elastic critical buckling loads for DSM, Schafer et al. [4] developed Finite Strip software CUFSM. Elastic critical buckling loads can also be calculated using Finite Element software such as ABAQUS [14]. In this research, the elastic critical buckling loads will be calculated using CUFSM. The effects of non-uniform temperatures in the cross-section are accounted for by inputting nonuniform distributions of the material modulus of elasticity. Nevertheless, to ensure that the CUFSM results are accurate, ABAQUS calculations have also been carried out and this section compares the results between using these two different methods.

In this study, the section was lipped channel section 100x50x15x1. The ends were simply supported (free rotation, free axial deformation, no transverse deformation). Along the length of the column, either there were restraints at every $300 \mathrm{~mm}$ intervals to prevent displacement in the horizontal direction (Figure 2) or there was no restraint. These restraints simulate the screws that attach thin-walled steel members to gypsum plaster boards that are often used in conjunction with thin-walled steel members. In ABAQUS simulations, these screws can be treated as discrete restraints. However, in CUFSM, since the Finite Strip Method is used, the restraint is applied to the entire line along the column.

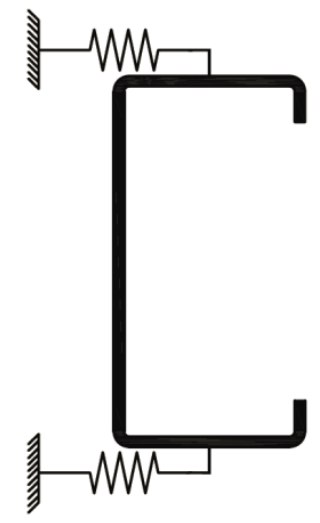

(a)

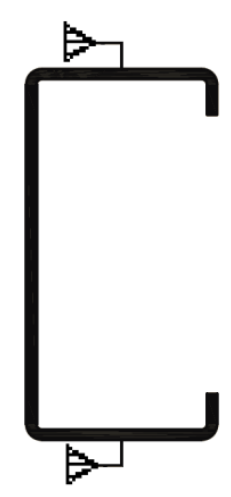

(b)

Figure 2. Intermediate Boundary Condition along the Column Length: (a) CUFSM, (b) ABAQUS

Figure 3 compares the CUFSM and ABAQUS simulation results. The agreement is excellent for columns without intermediate restraint. For columns with intermediate restraints, there is no difference in the calculated elastic local buckling and elastic global buckling results for all column lengths. For distortional buckling, because CUFSM calculations assume continues restraint along the entire column length, the CUFSM results are slightly higher. However, the minimum distortional buckling loads are very similar. Figure 3 also shows that the local buckling loads are the same regardless whether or not the columns have intermediate restraints. 


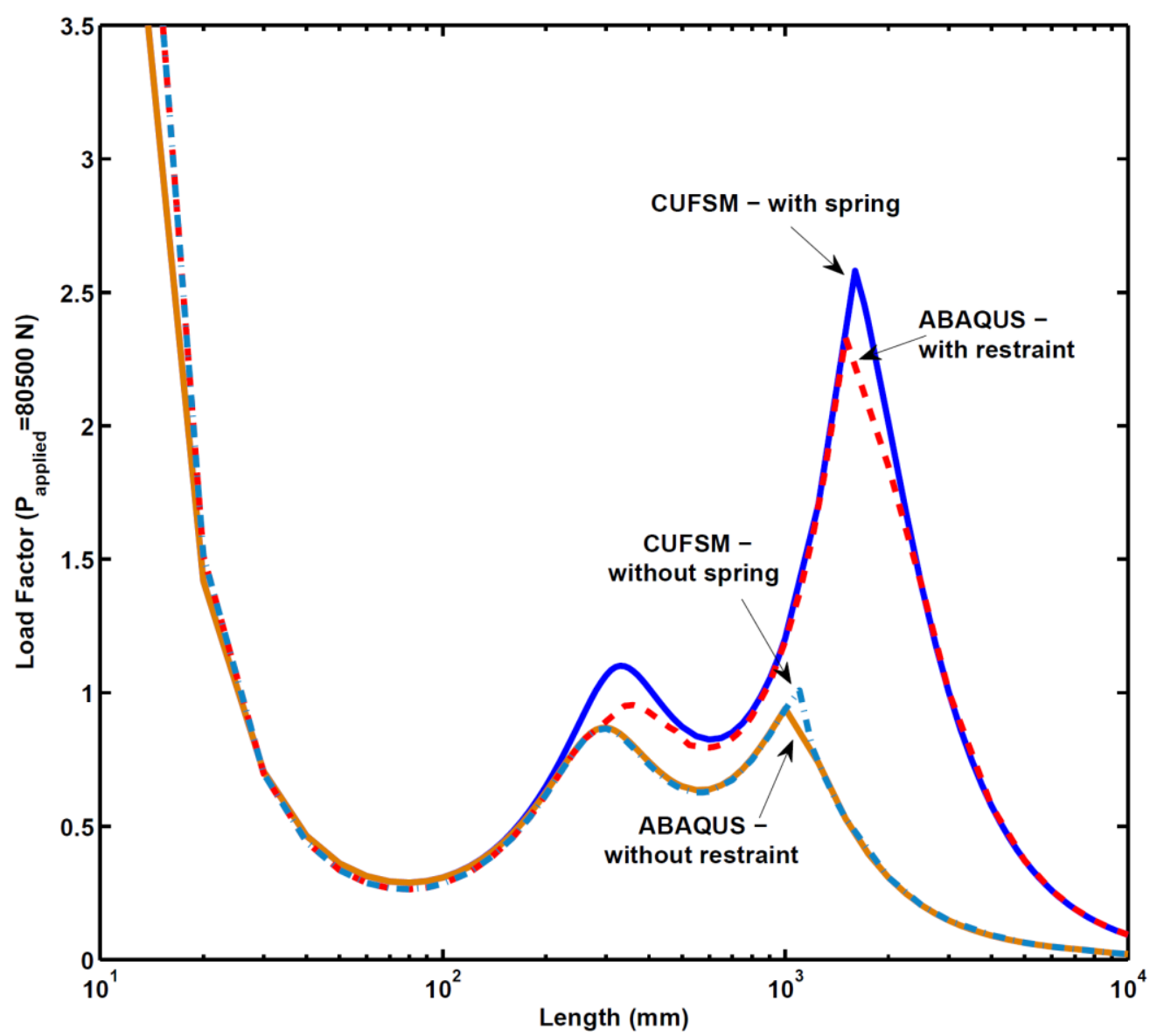

Figure 3. Comparison between CUFSM and ABAQUS Elastic Buckling Load Calculation Results for a Lipped Channel with and without Intermediate Restraints along the Length 


\section{Validation of ABAQUS Simulation Model}

Feng et al. [11] carried out 52 steady state tests on lipped and un-lipped channel sections (solid and perforated) at ambient and uniform elevated temperatures. To validate the author's ABAQUS simulation model, five of the tests on lipped channel $(100 \times 54 \times 15 \times 1.2)$ were simulated. These tests were performed on columns of $400 \mathrm{~mm}$ in length and tested at five temperature levels: ambient, $250^{\circ} \mathrm{C}, 400^{\circ} \mathrm{C}, 550^{\circ} \mathrm{C}$ and $700^{\circ} \mathrm{C}$. Feng et al. [8] also carried out numerical modelling of their test results using ABAQUS. Their simulation input data were used in this study, including the mechanical properties (Table 1 and Figure 4), the initial imperfection scale (equal to the thickness of the plate), the element type (S8R5) and mesh size $(7.5 \mathrm{~mm})$. The sensitivity study results in Table 2 clearly show that the mesh size is appropriate.

Table 1. Mechanical Properties from Tensile Coupon Test at Ambient Temperature [11]

\begin{tabular}{cccc}
\hline Test Specimen & $\begin{array}{c}\text { Mean Yield Stress } \\
\left(\mathrm{N} / \mathrm{mm}^{2}\right)\end{array}$ & $\begin{array}{c}\text { Mean Yield Stress } \\
\left(\mathrm{N} / \mathrm{mm}^{2}\right)\end{array}$ & $\begin{array}{c}\text { Mean Elastic Modulus } \\
\left(\mathrm{N} / \mathrm{mm}^{2}\right)\end{array}$ \\
\hline $100 \times 54 \times 15 \times 1.2$ & 410.58 & 526.02 & 186950
\end{tabular}

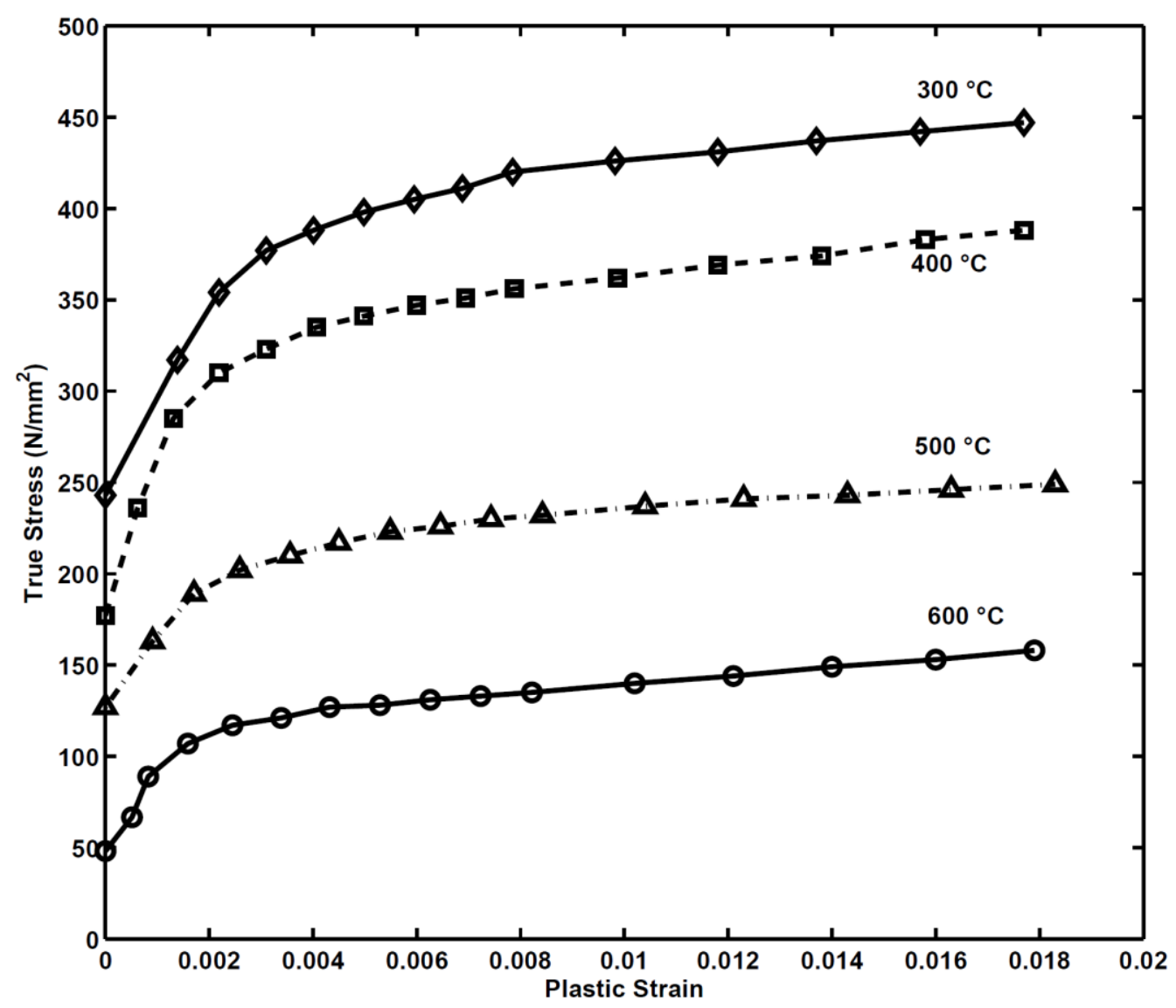

Figure 4. Stress-Strain Curve at Elevated Temperatures [8] 
Figure 5 compares the test and simulated deformed shapes of the five tests, and Table 3 compares the authors' simulation failure loads with the test results [11] and the simulation results of Feng et al. [8]. Shown in Table 3 are also the author's simulation results using element type S4.
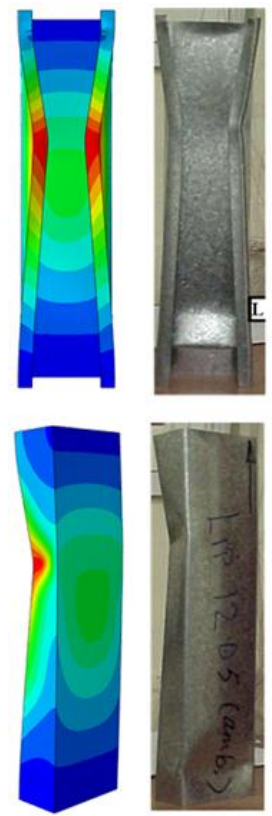

(a)
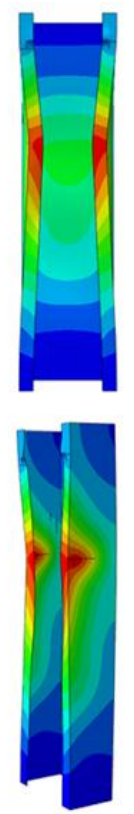

(b)
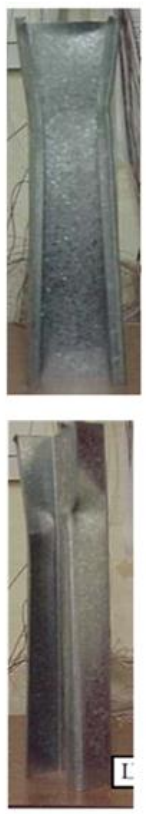

(b)
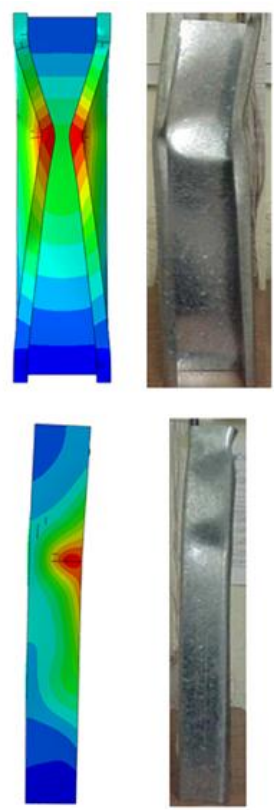

(c)
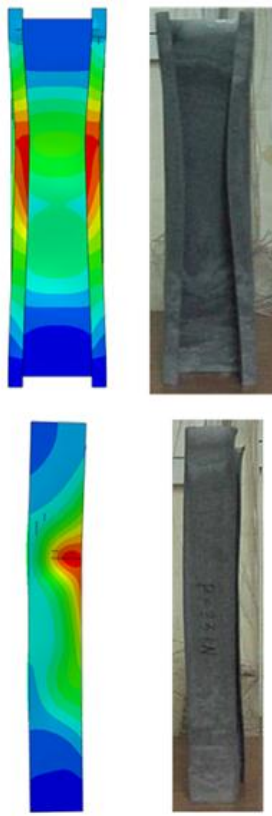

(d)
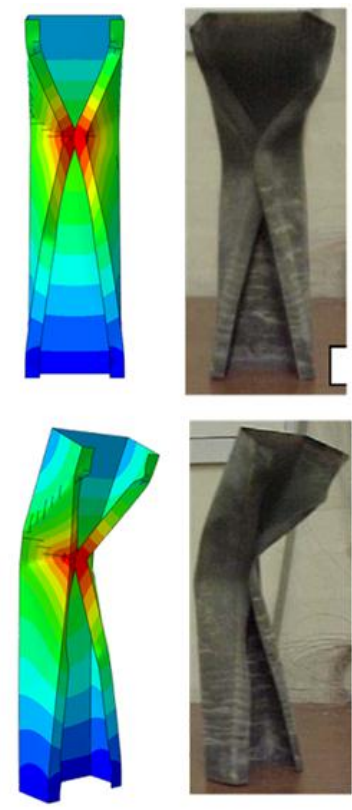

(e)

Figure 5. Comparison of Deformed Shapes of Short Channels between FE Modelling and Experimental [11] Results: (a) ambient, (b) $250^{\circ} \mathrm{C}$, (c) $400^{\circ} \mathrm{C}$, (d) $550^{\circ} \mathrm{C}$, (e) $700^{\circ} \mathrm{C}$

Table 2. Sensitivity Study for Mesh Size

\begin{tabular}{cc}
\hline Global Mesh Size $(\mathrm{mm})$ & Failure Load $(\mathrm{kN})$ \\
2.5 & 62.46 \\
5.0 & 62.53 \\
7.5 & 62.55
\end{tabular}

Table 3. Comparing Failure Load $(k N)$ between Finite Element Modelling and Experimental Results

\begin{tabular}{ccccc}
\hline $\begin{array}{c}\text { Temperature } \\
\left({ }^{\circ} \mathrm{C}\right)\end{array}$ & $\begin{array}{c}\text { This Research } \\
(\mathrm{S} 4)\end{array}$ & $\begin{array}{c}\text { This Research } \\
(\text { S8R5 })\end{array}$ & $\begin{array}{c}\text { Experimental Study } \\
{[11]}\end{array}$ & $\begin{array}{c}\text { Simulation of Feng et al. } \\
{[8]}\end{array}$ \\
\hline Ambient & 63.05 & 62.55 & 55.99 & 61.22 \\
250 & 52.07 & 51.66 & 53.16 & 54.06 \\
400 & 40.95 & 40.59 & 45.75 & 40.08 \\
550 & 26.24 & 26.04 & 27.00 & 25.81 \\
700 & 7.98 & 7.94 & 8.85 & 7.82
\end{tabular}

This comparison indicates that the authors' simulation results are accurate, for both the deformation shapes and failure loads of the columns. 


\section{Results of Numerical Parametric Studies for Ultimate Strength of Lipped Channels at Elevated}

\section{Temperatures}

The validated ABAQUS model for local buckling has been used to perform a series of parametric studies to generate a comprehensive database for the assessment of DSM.

The yield stress and elastic modulus of steel were taken as 350 and $205000 \mathrm{~N} / \mathrm{mm}^{2}$ respectively. The elevated temperature stress-strain relationships were derived based on Eurocode EN 1993-1-2 [18] and are shown in Figure 6.

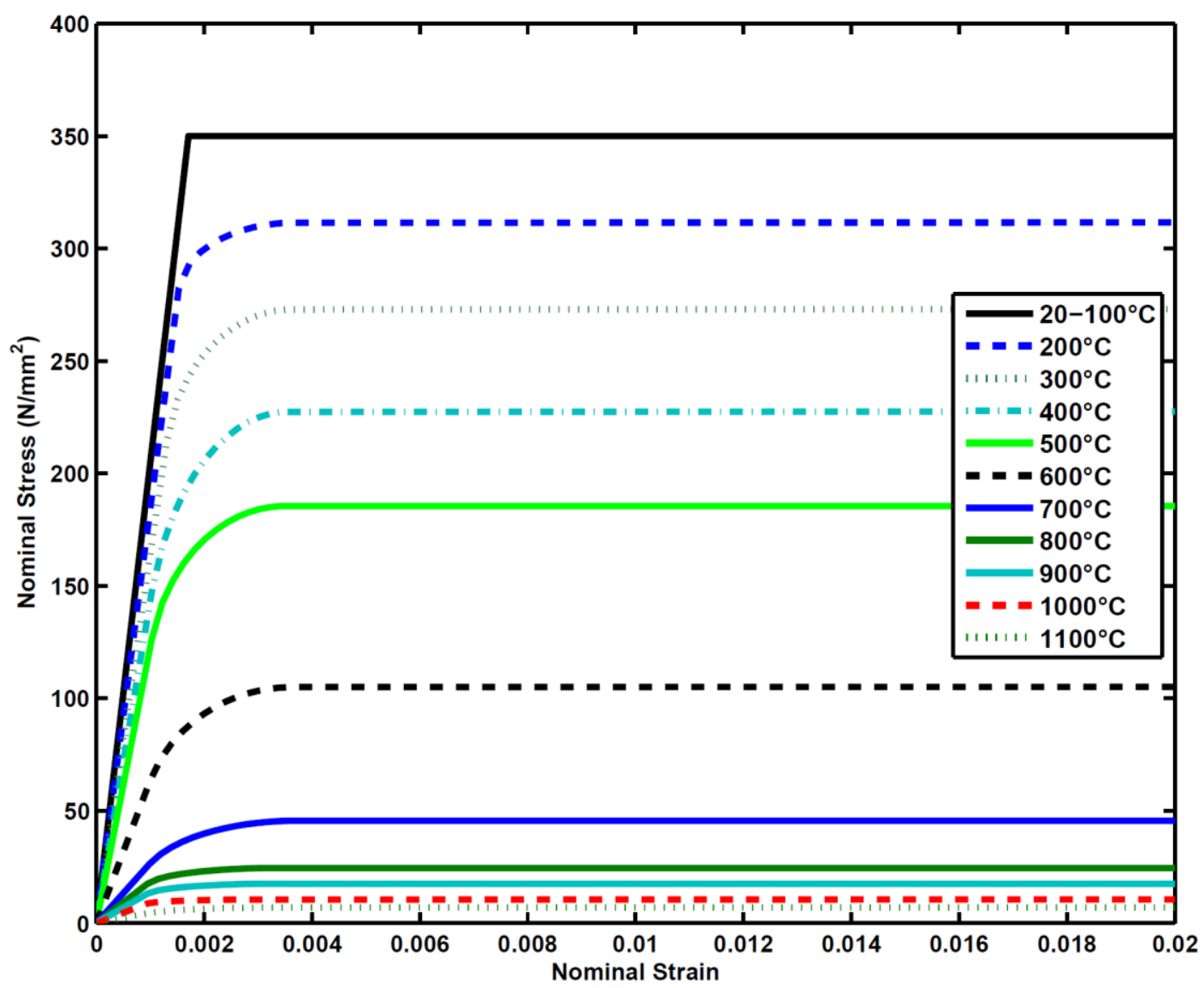

Figure 6. Stress-Strain Relationship of Steel at Different Temperatures based on Eurocode EN 1993-1-2 [18]

It should be mentioned that in the parametric study, shell element type S4 was used. The author's research [3] and that of Schafer et al. [19] confirm that using S4 gives almost identical results.

In order to include the effects of interaction between local and global buckling, the lowest eigenvalue of both buckling modes were included in specifying the column's imperfections. The maximum local initial imperfection was set equal to the thickness of the plate, according to the sensitivity study results of the authors [3] and Feng et al. [8, 12]. The global initial imperfection was assumed to be equal to L/500 ( $\mathrm{L}$ is the length of the column), based on the recommendations of Feng et al. [12] and Kaitila [20]. 
Three sets of parametric studies were performed, one at ambient temperature, one at uniform elevated temperatures and one with non-uniform temperature distributions in the cross-section. For the nonuniform temperature distributions case, each flange and the associated lip were assumed to have the same temperature and the temperature distribution in the web was linear. This temperature distribution, shown in Figure 7, was found by Feng et al. [9] to be sufficiently accurate for the purpose of calculating load bearing capacities for thin-walled steel columns with insulation boards on both sides and exposed to fire attack on one side.

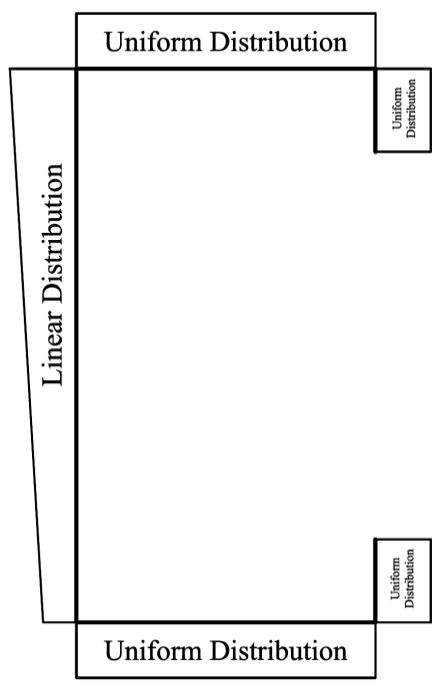

Figure 7. Assumed Temperature Distiburtion in the Cross-Section

The column ends were assumed to be simply supported (Figure 8). Within the length, the column was either completely unrestrained or restrained from horizontal movements in the plane of the flanges (to simulate connections to gypsum boards) along the centre line of the flanges at $300 \mathrm{~mm}$ intervals.

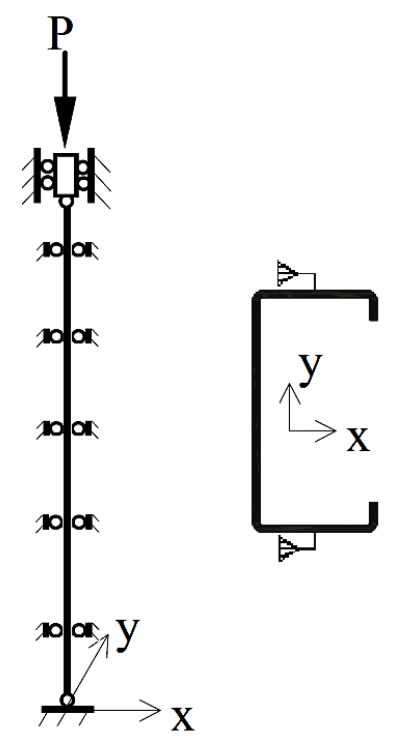

Figure 8. Boundary Conditions and Loading 
The Riks method was used at ambient and uniform elevated temperatures. For columns with non-uniform temperature distributions, the transient state analysis was followed: applying the mechanical load to reach the desired level then followed by increasing the temperatures while maintaining the applied mechanical load. It was not possible to apply the Riks method under transient state analysis, so the general method in ABAQUS was used.

The numerical parametric studies were performed to investigate the effects of varying the following design parameters: cross-section dimensions (flange width, thickness and lip length), column length, temperature profiles, load levels and intermediate support conditions. Table 4 lists the ranges of column dimension, boundary condition and length. Three non-uniform temperature distributions were considered, the lower temperature being $1 / 3,1 / 2$ or $2 / 3$ of the higher temperature respectively.

In total, 35 simulations were performed at the ambient temperature to confirm the accuracy of the Direct Strength Method for local buckling. 217 simulations were made at uniform elevated temperatures, with temperatures varying from $200^{\circ} \mathrm{C}$ to $800^{\circ} \mathrm{C}$. For non-uniform temperature distributions, a total 120 simulations were performed consisting of four different load ratios (from 30 to 65\%), three temperature profiles (1200/400, 1200/600 and 1200/800 at 120min), and other variables as mentioned before.

Table 4. Cross-Section Dimensions for Numerical Study

\begin{tabular}{|c|c|c|}
\hline $\begin{array}{c}\text { web } \times \text { flange } \times \text { lip } \times \text { thickness } \\
(\mathrm{mm})\end{array}$ & $\begin{array}{l}\text { Boundary Condition } \\
\text { along the Length }\end{array}$ & $\begin{array}{l}\text { Lengths } \\
(\mathrm{mm})\end{array}$ \\
\hline $100 \times 50 \times 15 \times 0.8$ & Bare & $200-1000-1500-2000-2500$ \\
\hline $100 \times 50 \times 15 \times 0.8$ & Restrained & $600-3000-5100-6000$ \\
\hline $100 \times 50 \times 15 \times 1$ & Bare & $200-1000-1500-2000$ \\
\hline $100 \times 50 \times 15 \times 1$ & Restrained & $3600-4800-5400$ \\
\hline $100 \times 50 \times 15 \times 1.5$ & Bare & $900-1250$ \\
\hline $100 \times 50 \times 15 \times 1.5$ & Restrained & $2100-3000-3600$ \\
\hline $100 \times 50 \times 15 \times 1.8$ & Bare & $800-1000$ \\
\hline $100 \times 50 \times 15 \times 1.8$ & Restrained & $1500-3000$ \\
\hline $100 \times 54 \times 15 \times 1.2$ & Bare & $1000-1200-1500$ \\
\hline $100 \times 54 \times 15 \times 1.2$ & Restrained & $3600-4500$ \\
\hline $100 \times 35 \times 10 \times 1.5$ & Bare & $900-1000$ \\
\hline $100 \times 35 \times 10 \times 1.5$ & Restrained & $2100-3000$ \\
\hline $100 \times 45 \times 10 \times 0.8$ & Bare & 200 \\
\hline
\end{tabular}




\section{Assessment of the Direct Strength Method}

\subsection{Assessment Results for Ambient and Uniform Elevated Temperatures}

The critical elastic buckling loads were calculated by using the freely available elastic eigenvalue analysis software CUFSM [4]. The column squash load was obtained by multiplying the gross cross-sectional area of the column by the yield stress of the steel at the specified temperature.

At elevated temperatures, even though the steel stress-strain relationship becomes curved, the elastic buckling load was calculated using the initial elastic modulus at the elevated temperature. As will be shown later (Figure 15), the actual shape of the stress-strain relationship of steel has only minor effect on the column resistance.

Figures 9 and 10 compare the FE simulation with DSM calculation results for ambient and uniform elevated temperatures respectively. Included in the figures are also the experimental results of Feng et al. [11].

The agreement between the FE simulation and DSM calculation results is similar to that reported in the review paper of Schafer [21], which compares the DSM calculation results with available test results. The ambient temperature comparison indirectly validates the simulation results of this paper. The elevated temperature result comparison confirms that the DSM is suitable for uniform elevated temperature applications without modification, despite some changes in the shape of the steel stress-strain curves at elevated temperatures. The average difference was $6.35 \%$ for the ambient temperature results and $8.11 \%$ for the uniform temperature results. 

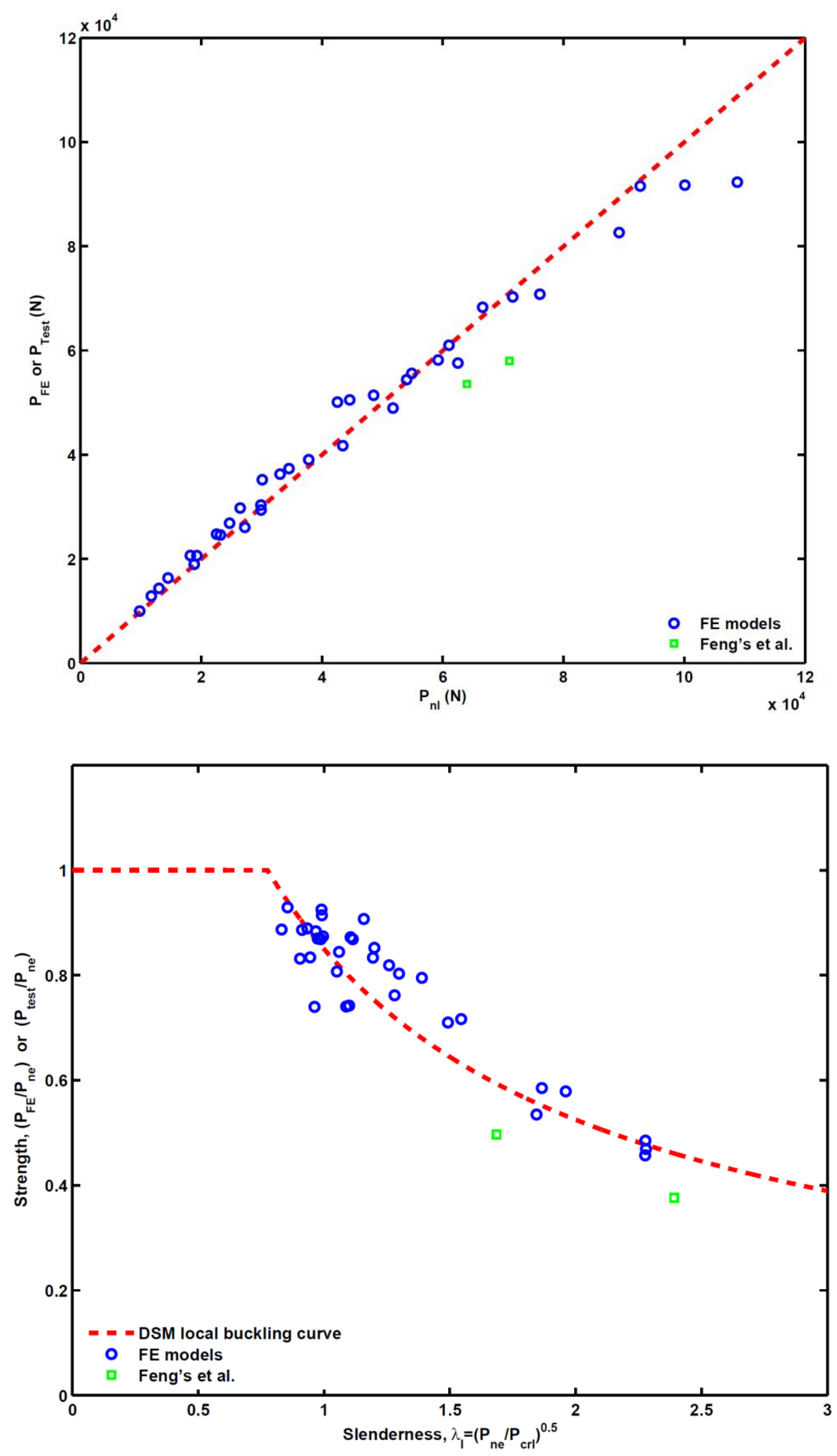

Figure 9. Comparison between FE Simulation, Feng's et al. [11] Test and DSM Calculation Results at Ambient Temperature 

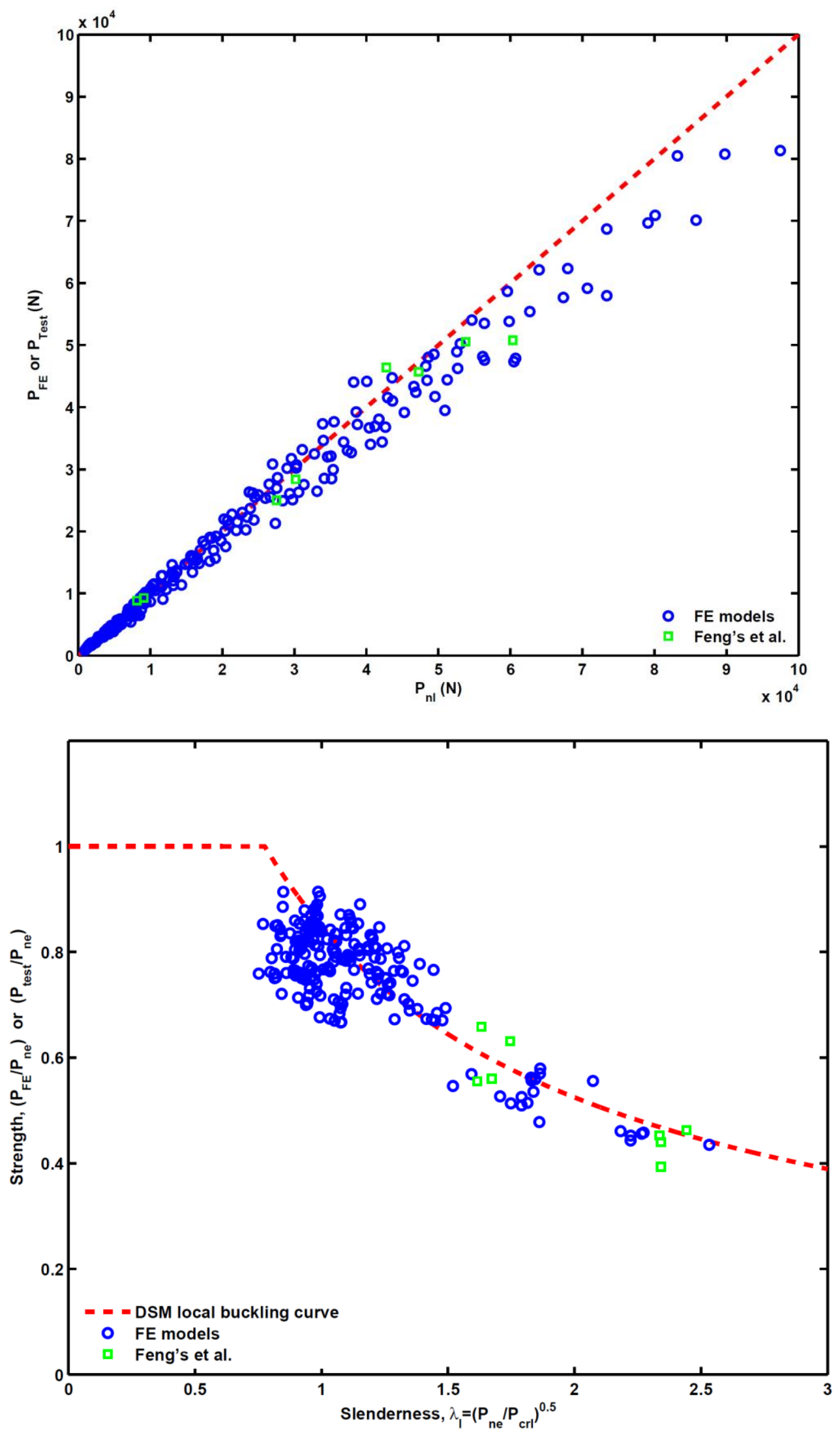

Figure 10. Comparison between FE Simulation, Feng's et al. [11] Test and DSM Calculation Results with Uniform Temperature 


\subsection{Assessment Results for Non-Uniform Elevated Temperatures}

For members with non-uniform temperature in the cross-section, two additional effects should be considered:

- Thermal bowing caused by differential thermal expansion on the two sides of the cross-section.

- Shift of resistance due to non-uniform distribution of resistance (yield stress) of the steel.

These effects will cause additional bending moments when the member is under compressive load and should be considered when calculating both the elastic buckling and squash loads. Conceptually, it may be possible to devise an interaction equation for combined axial load and bending, as in conventional methods at ambient temperature for hot-rolled beam-columns. However, this was not pursued in this research for two reasons: (1) the direct strength method for thin-walled structures has only been accepted for columns under axial load and this research intends to adapt this approach for the non-uniform temperature problem; (2) for the elastic buckling load calculation, by defining different mechanical properties of the steel at different elevated temperatures, the shift in the centre of resistance is already considered and cannot be separated to give an additional bending moment, although the thermal bowing effect should be considered as an additional bending moment.

The direct strength method requires calculations of the elastic critical loads, discussed above, and the column cross-sectional squash load. This research seeks to find an "effective" squash load to allow for the effects of non-uniform temperature induced bending. The effective squash load of the member is the axial load value that causes the cross-section with non-uniform temperature to reach the cross-section limit under combined axial load and bending.

The effective squash load is obtained using the following procedure [3]:

(1) Evaluate the plastic axial load - bending moment interaction curve of the cross-section. To do so, the cross-section is assumed to have reached yield stress everywhere and a neutral axis divides the crosssection into a tensile and a compressive area. Taking moment about the centre of resistance of the crosssection with non-uniform temperature distribution, the bending moment and net axial force give one point on the bending moment - axial force interaction curve. By moving the neutral axis from one edge of the cross-section to the other, the bending moment - axial force curve for the cross-section with non-uniform temperature distribution can be obtained.

(2) In the top and bottom of the cross-section, there is only shift of the centre of resistance. In the middle of the column, both thermal bowing and shift of the centre of resistance exist and they are in opposite directions. Thus, the bending moments at the ends and in the middle of the column are different. The effective squash load of the column is the one that gives the least value based on these two bending moments.

Details of calculating the elastic buckling and effective squash load for columns with non-uniform temperature distributions in the cross-sections is explained in Shahbazian and Wang [3]. 
Having calculated the column effective squash load and the critical elastic global buckling load, the column ultimate strength for global buckling can be calculated. For columns with non-uniform temperature distributions in the cross-sections, the authors recently proposed [3] equations 10 and 11 to replace the DSM equations.

To calculate the column strengths under local buckling, the results from equations 10 and 11 were substituted into equations 7-9. Figure 11 compares the calculation results with the ABAQUS simulation results. It clearly shows that the existing DSM equations for local buckling are not sufficiently accurate for columns with non-uniform temperature distributions, with the existing DSM equations tending to produce higher values, thus being on the unsafe side, particularly when the local buckling slenderness is high. Modification is necessary, and it is suggested to replace the original DSM equations for local buckling (equations 8 and 9) with the following equations for columns with non-uniform temperature distributions in the cross-section:

$$
\begin{gathered}
\text { for } \lambda_{l} \leq 0.776=P_{n l} \\
\text { for } \lambda_{l}>0.776 \\
P_{n l}=\left(1-0.22\left(\frac{P_{c r l}}{P_{n e}}\right)^{0.75}\right)\left(\frac{P_{c r l}}{P_{n e}}\right)^{0.75} P_{n e}
\end{gathered}
$$

Figure 12 compares the FE simulation results with calculation results using the proposed new local buckling equations. The agreement between the FE simulation results and the DSM calculation results is now comparable (average difference 14.32\%) to that under uniform temperature (see Figure 10), particularly for columns with high local buckling slenderness.

For columns with low local buckling slenderness, the spread is quite high. This is mainly due to the effects of using different temperature distributions. Figure 13 shows the comparison between ABAQUS simulation results and DSM calculation results for each of the three different temperature profiles used in the simulations. For each temperature profile, the simulation results are populated within a relatively narrow band. However, because the result bands for different temperature profiles do not coincide, the overall comparison between the ABAQUS simulation results and the DSM calculation results (see Figure 12) shows wider discrepancy. Figure 12 indicates that the new proposed DSM equations for non-uniform temperature distribution are below the original DSM equations for ambient or uniform temperature distribution. The results in Figure 13 reflect a gradual change in the same way, with the ABAQUS simulation results being higher for columns with more uniformity of temperature distribution, i.e. results for profile 3 (temperature ratio $2 / 3$ ) > results for profile 2 (temperature ratio $1 / 2$ ) > results for profile 1 (temperature ratio 1/3). Nevertheless, this movement is small. Bearing in mind the simplicity of the approach and the wide range of temperature profiles, it is considered that DSM is applicable and the proposed new DSM equations for local buckling (equations 12 and 13) are sufficiently accurate. Table A1 in Appendix A presents the full calculation data. 

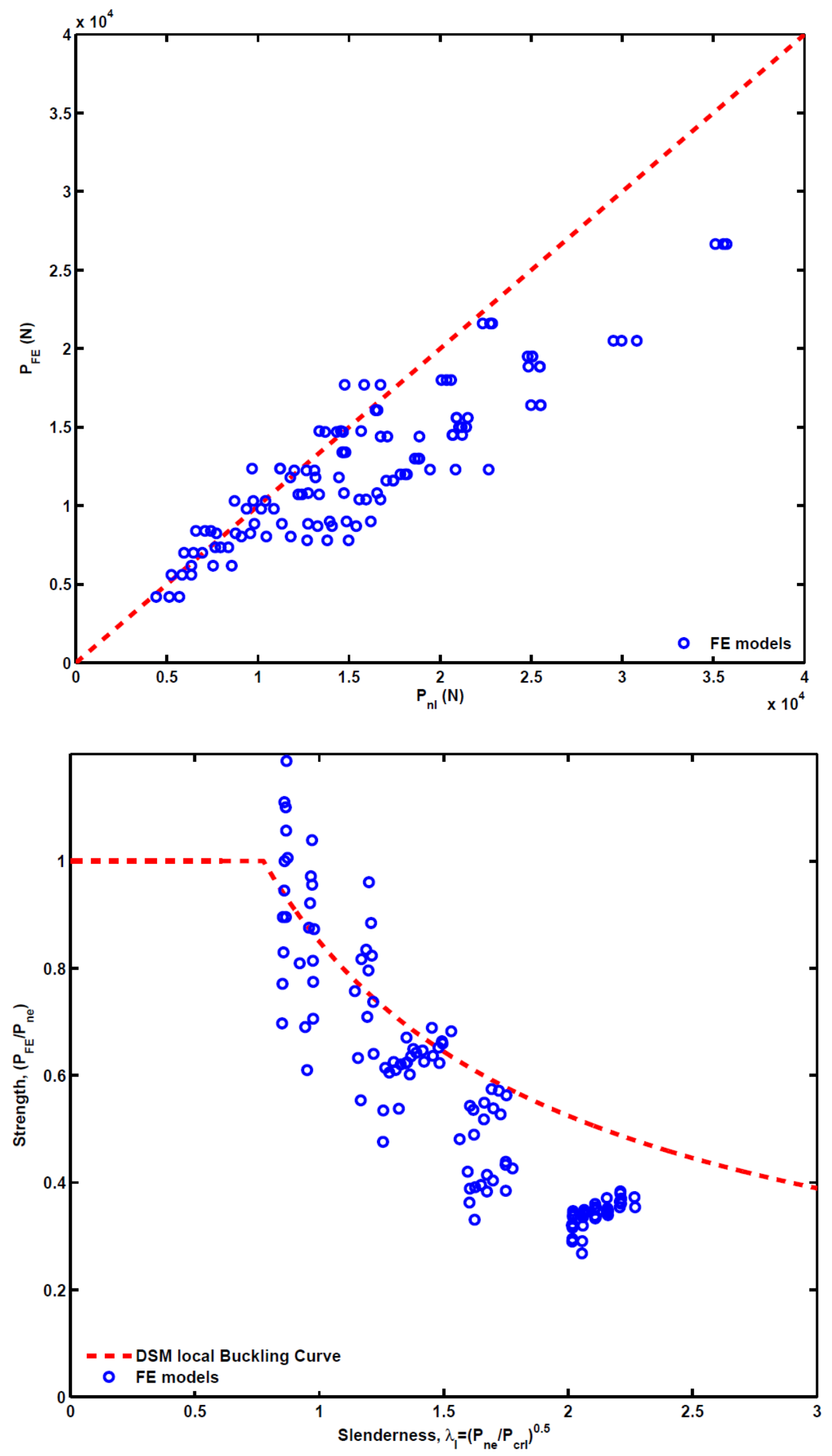

Figure 11. Comparison between FE Results with DSM Calculation Results using Equations 8 and 9 

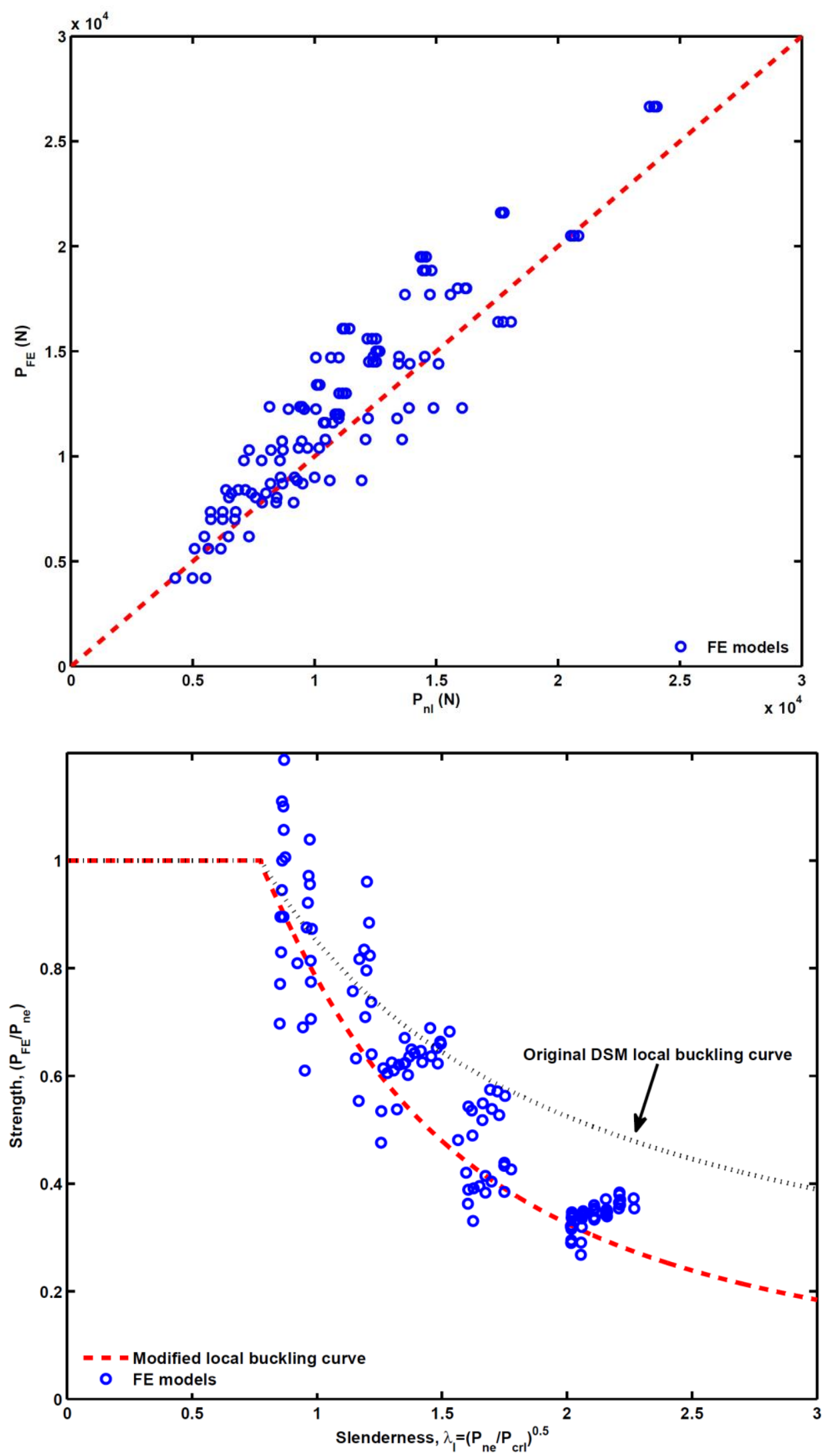

Figure 12. Comparison between FE Results with Calculation Results using Modified DSM Equations for Local Buckling (equations 12 and 13) 

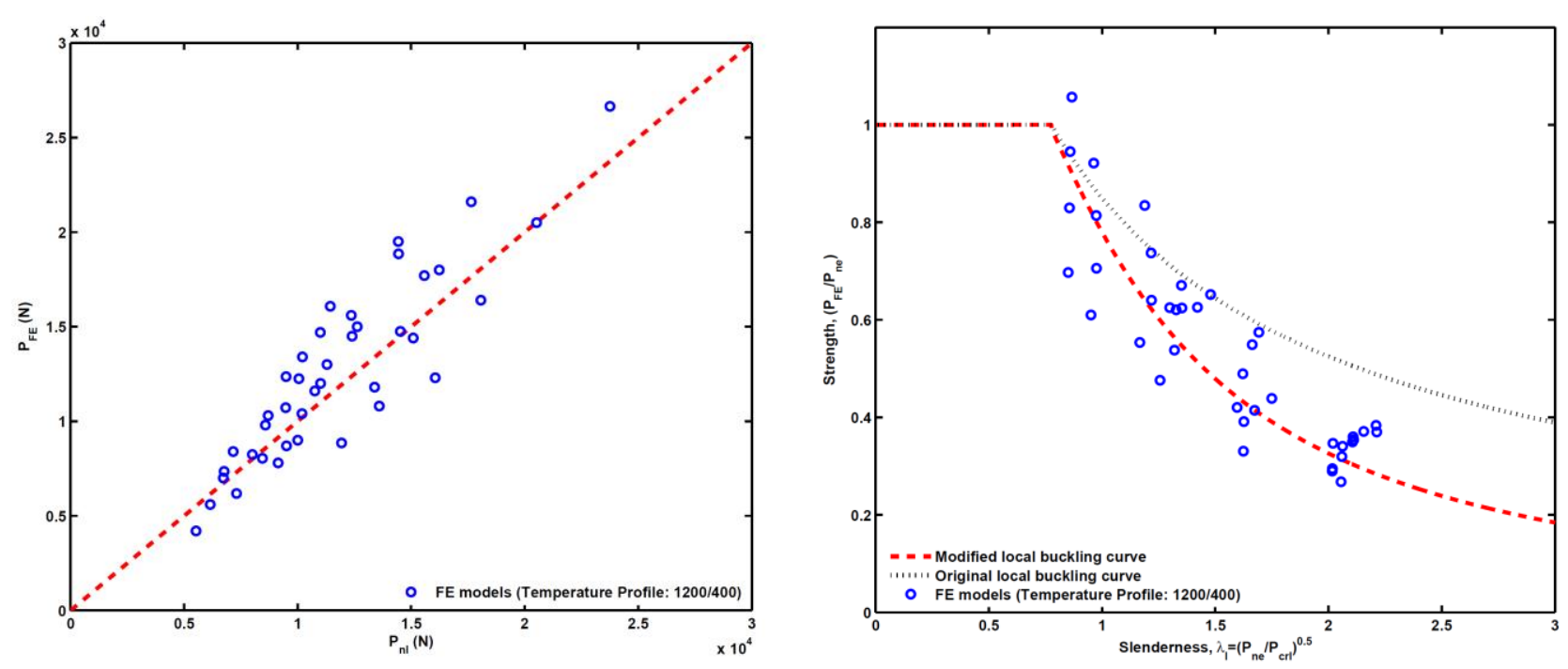

(a)
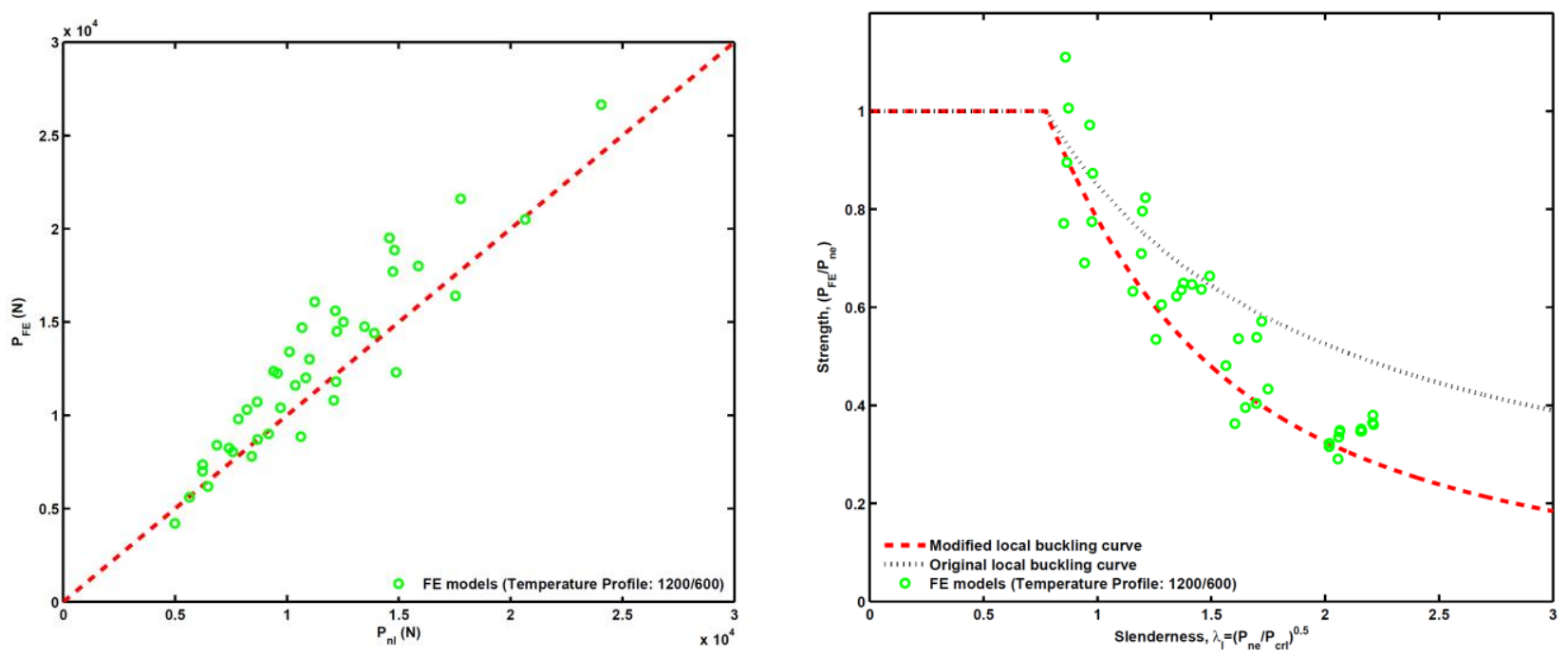

(b)
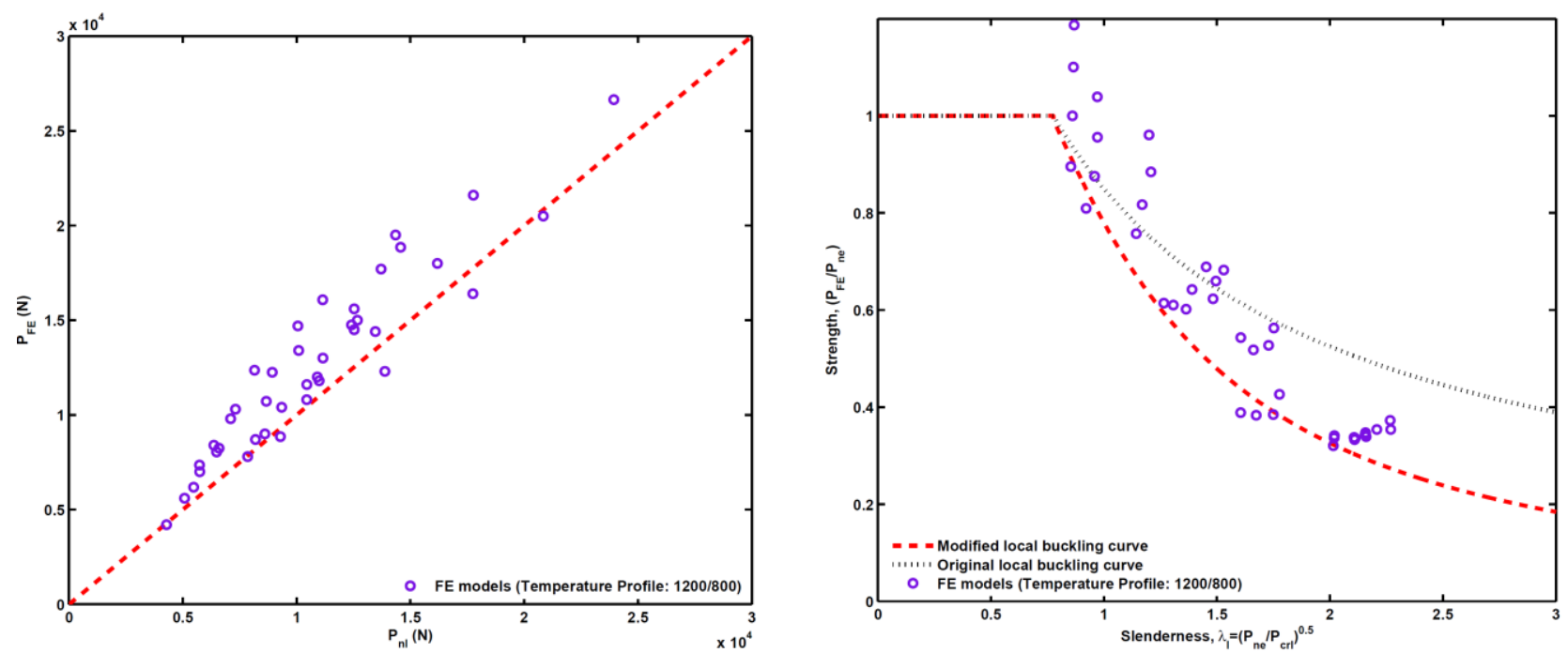
(c)

Figure 13. Comparison between FE Results with DSM Calculation Results for Different Temperature Profiles: (a) Temperature Profile 1 (1200/400 at 120 minutes), (b) Temperature Profile 2 (1200/600 at 120 minutes), (c) Temperature Profile $3(1200 / 800$ at 120 minutes)

\section{Effects of Stress-Strain Relationship of Steel}

In the original development of DSM at ambient temperature, the steel stress-strain relationship was assumed to be linear elastic and plastic. At elevated temperatures, the stress-strain relationship of steel becomes more curvilinear. Table 5 and Figure 14 compare the ABAQUS simulation results between using the stress-strain relationship of steel at elevated temperatures according to Eurocode EN 1993-1-2 (see Figure 7) and idealised linear elastic plastic relationships shown in Figure 15. The column crosssection dimensions were 100x50x15x0.8 and the column length was $2000 \mathrm{~mm}$ without intermediate restraints.

It can be seen from the results in Table 5 and Figure 14 that the effects of using different stress-strain curves are minor, provided the same initial modulus of elasticity and the maximum stress are maintained.

Table 5. Comparison of ABAQUS Simulation Results between using Different Stress-Strain Relationships of Steel at Elevated Temperatures

\begin{tabular}{cccc}
\hline \multirow{2}{*}{$\begin{array}{c}\text { Temperature } \\
\text { Profile }\end{array}$} & $\begin{array}{c}\text { Applied Load } \\
(\mathrm{N})\end{array}$ & $\begin{array}{c}\text { Curved Stress-Strain } \\
\text { Relationship }\end{array}$ & $\begin{array}{c}\text { Failure Time (min) } \\
\text { Elastic-Plastic Stress-Strain } \\
\text { Relationship }\end{array}$ \\
\hline $1200 / 400$ & 4200.00 & 55.22 & 55.33 \\
$1200 / 400$ & 5600.00 & 48.09 & 48.62 \\
$1200 / 400$ & 7000.00 & 37.61 & 38.52 \\
$1200 / 400$ & 8400.00 & 29.19 & 30.03 \\
$1200 / 600$ & 4200.00 & 56.59 & 56.84 \\
$1200 / 600$ & 5600.00 & 50.57 & 50.98 \\
$1200 / 600$ & 7000.00 & 41.20 & 42.32 \\
$1200 / 600$ & 8400.00 & 32.32 & 33.38 \\
$1200 / 800$ & 4200.00 & 58.01 & 58.42 \\
$1200 / 800$ & 5600.00 & 52.80 & 53.32 \\
$1200 / 800$ & 7000.00 & 45.78 & 47.05 \\
$1200 / 800$ & 8400.00 & 36.20 & 37.55
\end{tabular}




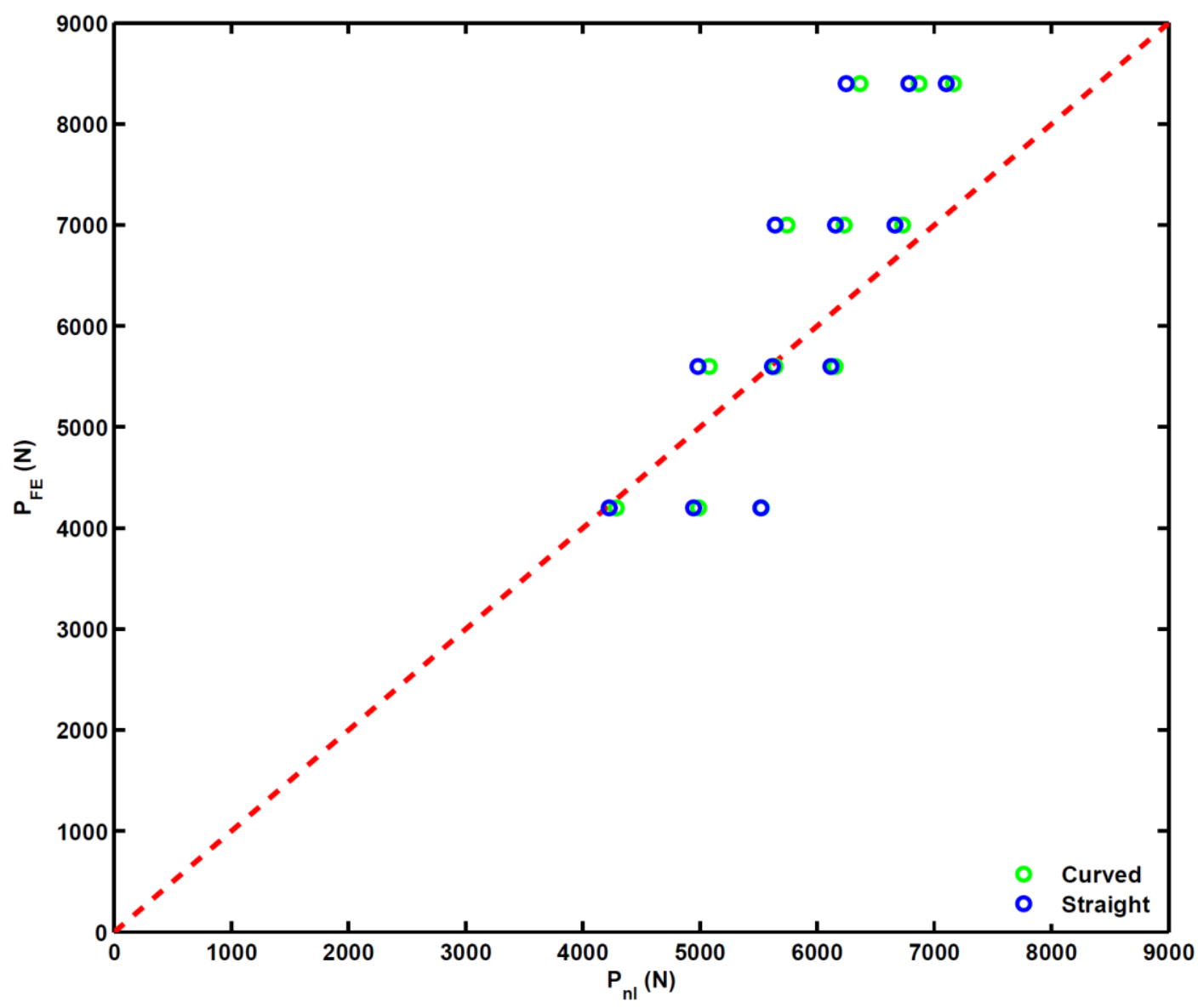

Figure 14. Comparison between ABAQUS Simulation Results with Modified DSM Local Buckling Results for using Different StressStrain Curves of Steel at Elevated Temperatures 


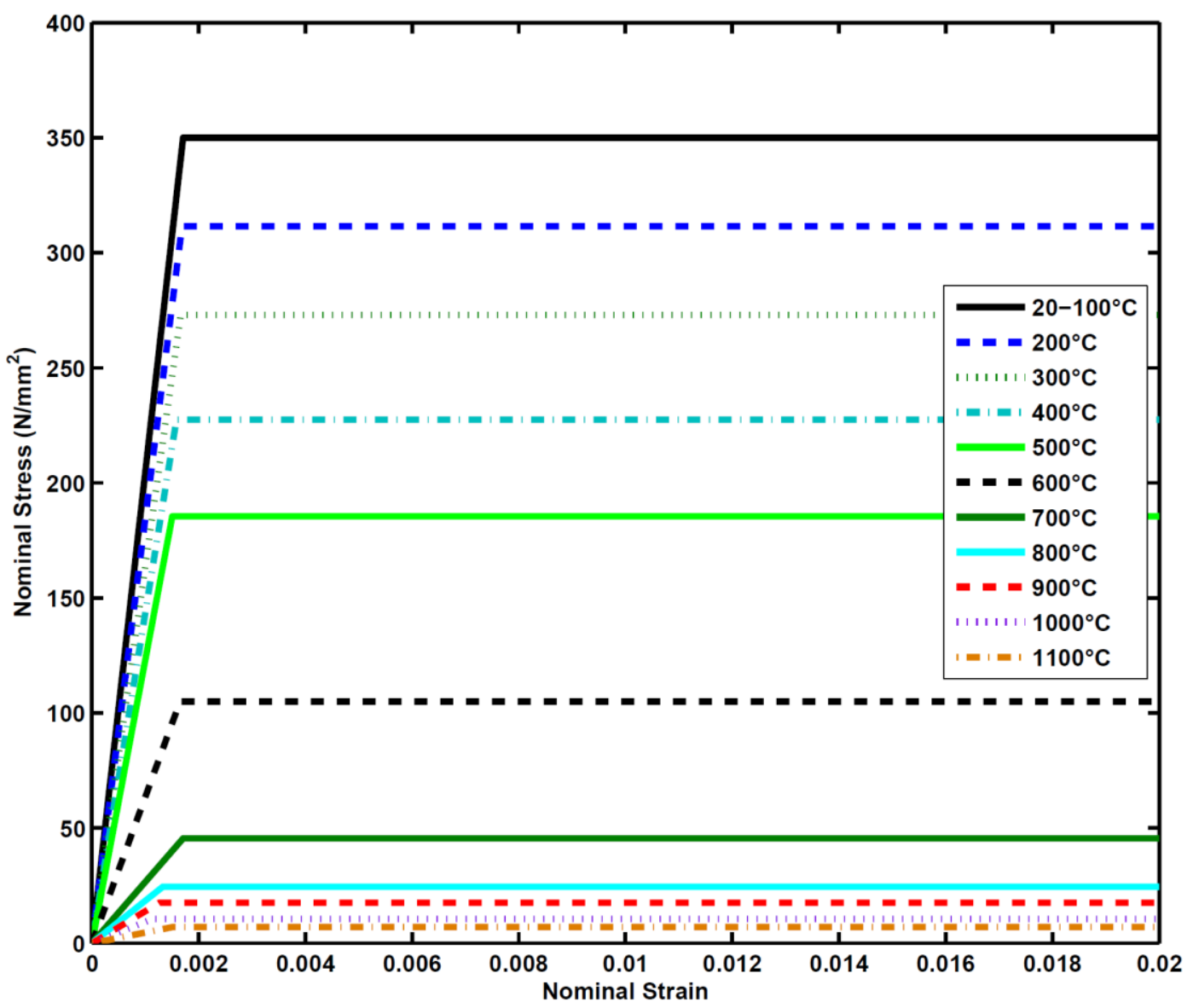

Figure 15. Idealised Linear Elastic-Plastic Stress-Strian Curve of Steel at Elevated Temperatures 


\section{Conclusions}

This paper has presented the results of a numerical simulation and analytical study to investigate the applicability of the Direct Strength Method to thin-walled steel columns with uniform and non-uniform temperature distributions in the cross-section under local buckling. The following conclusions may be drawn:

(1) For uniform temperature applications, the DSM equations in the AISI specification [2] are directly applicable without modification.

(2) For cross-sections with non-uniform temperature distributions, DSM may still be applied, but new local buckling equations should be used. They are given as equations 12 and 13 in this paper. This curve gives lower column strength than the original DSM equations for local buckling.

(3) The degree of temperature distribution, measured as the ratio of the lower temperature in one flange to the higher temperature in the other flange of the cross-section, has some influence on the spread of FE modelling results, with a higher degree of temperature distribution giving higher simulation results. But the change is relatively small for the wide range of temperature profiles included in this study.

(4) The shape of the stress-strain curve of steel at elevated temperatures has little effect on the simulated column strengths using ABAQUS. 
Appendix A

Table A.1. Data for Models with Non-UniformTemperatures

\begin{tabular}{|c|c|c|c|c|c|c|c|c|c|c|c|}
\hline Model & $\begin{array}{c}\text { Temperature } \\
\text { Profile }\end{array}$ & Failure time & $\begin{array}{l}\text { Temperature on } \\
\text { Exposed Side }\end{array}$ & $\begin{array}{l}\text { Temperature on } \\
\text { Unexposed Side }\end{array}$ & $\begin{array}{c}\text { Load Ratio } \\
(\%)\end{array}$ & $\mathrm{P}_{\mathrm{FE}}$ & $\mathrm{P}_{\mathrm{y}}$ & $\mathrm{P}_{\mathrm{crl}}$ & $\mathrm{P}_{\text {cre }}$ & $P_{n e}$ & $\mathrm{P}_{\mathrm{nl}}$ \\
\hline \multirow{12}{*}{$\begin{array}{c}100 \times 50 \times 15 \times 0.8 \\
\text { Bare } \\
200 \mathrm{~mm}\end{array}$} & $1200 / 400$ & 60.75 & 617 & 212 & 30 & 8700.00 & 30223.00 & 7253.52 & 892736.04 & 29512.00 & 9510.63 \\
\hline & $1200 / 400$ & 56.08 & 571 & 198 & 40 & 11600.00 & 34166.00 & 8199.84 & 1125947.36 & 33444.69 & 10759.71 \\
\hline & $1200 / 400$ & 46.88 & 481 & 168 & 50 & 14500.00 & 41787.00 & 9193.14 & 1476167.56 & 40963.41 & 12398.51 \\
\hline & $1200 / 400$ & 29.43 & 309 & 113 & 65 & 18850.00 & 52037.00 & 10407.40 & 1751596.64 & 50961.18 & 14446.92 \\
\hline & $1200 / 600$ & 60.48 & 615 & 312 & 30 & 8700.00 & 27595.00 & 6622.80 & 856179.03 & 26976.61 & 8686.74 \\
\hline & $1200 / 600$ & 53.67 & 548 & 279 & 40 & 11600.00 & 33903.00 & 7797.69 & 1195521.49 & 33233.62 & 10372.93 \\
\hline & $1200 / 600$ & 42.64 & 439 & 226 & 50 & 14500.00 & 42576.00 & 8940.96 & 1499071.16 & 41734.11 & 12231.54 \\
\hline & $1200 / 600$ & 26.67 & 282 & 149 & 65 & 18850.00 & 53351.00 & 10670.20 & 1756597.68 & 52223.64 & 14809.63 \\
\hline & $1200 / 800$ & 58.93 & 600 & 403 & 30 & 8700.00 & 26018.00 & 6244.32 & 866565.92 & 25474.44 & 8194.28 \\
\hline & $1200 / 800$ & 50.38 & 515 & 347 & 40 & 11600.00 & 35217.00 & 7747.74 & 1284356.95 & 34544.46 & 10451.15 \\
\hline & $1200 / 800$ & 39.78 & 411 & 279 & 50 & 14500.00 & 43627.00 & 9161.67 & 1495690.62 & 42741.27 & 12531.41 \\
\hline & $1200 / 800$ & 24.31 & 259 & 178 & 65 & 18850.00 & 54402.00 & 10336.38 & 1758261.76 & 53231.13 & 14568.99 \\
\hline \multirow{12}{*}{$\begin{array}{c}100 \times 50 \times 15 \times 0.8 \\
\text { Bare } \\
1000 \mathrm{~mm}\end{array}$} & $1200 / 400$ & 58.96 & 600 & 207 & 30 & 8040.00 & 31275.00 & 7506.00 & 44742.02 & 19130.40 & 8449.55 \\
\hline & $1200 / 400$ & 55.16 & 562 & 195 & 40 & 10720.00 & 34691.00 & 8325.84 & 53028.66 & 21899.27 & 9473.59 \\
\hline & $1200 / 400$ & 51.37 & 525 & 183 & 50 & 13400.00 & 38371.00 & 8825.33 & 59624.70 & 24404.43 & 10213.03 \\
\hline & $1200 / 400$ & 41.66 & 430 & 152 & 60 & 16080.00 & 44415.00 & 9771.30 & 67648.49 & 27991.17 & 11442.06 \\
\hline & $1200 / 600$ & 60.43 & 614 & 312 & 30 & 8040.00 & 27332.00 & 6833.00 & 39079.29 & 16713.94 & 7584.15 \\
\hline & $1200 / 600$ & 55.98 & 570 & 291 & 40 & 10720.00 & 31800.00 & 7632.00 & 48262.86 & 20008.06 & 8674.36 \\
\hline & $1200 / 600$ & 48.20 & 494 & 253 & 50 & 13400.00 & 39159.00 & 8614.98 & 60692.53 & 24876.54 & 10114.87 \\
\hline & $1200 / 600$ & 38.51 & 399 & 206 & 60 & 16080.00 & 45204.00 & 9492.84 & 67078.22 & 28143.06 & 11243.41 \\
\hline & $1200 / 800$ & 60.25 & 612 & 412 & 30 & 8040.00 & 23916.00 & 5739.84 & 35015.42 & 14794.48 & 6486.23 \\
\hline & $1200 / 800$ & 53.05 & 542 & 365 & 40 & 10720.00 & 32589.00 & 7495.47 & 50493.40 & 20699.79 & 8670.24 \\
\hline & $1200 / 800$ & 43.45 & 447 & 302 & 50 & 13400.00 & 40473.00 & 8499.33 & 61102.09 & 25402.53 & 10093.68 \\
\hline & $1200 / 800$ & 35.02 & 364 & 248 & 60 & 16080.00 & 46518.00 & 9303.60 & 67032.44 & 28555.42 & 11146.02 \\
\hline \multirow{12}{*}{$\begin{array}{c}100 \times 50 \times 15 \times 0.8 \\
\text { Bare } \\
1500 \mathrm{~mm}\end{array}$} & $1200 / 400$ & 55.72 & 568 & 196 & 30 & 6180.00 & 34166.00 & 8199.84 & 21476.75 & 11162.49 & 7311.01 \\
\hline & $1200 / 400$ & 49.92 & 511 & 178 & 40 & 8240.00 & 39422.00 & 8672.84 & 24761.35 & 12868.45 & 8005.60 \\
\hline & $1200 / 400$ & 41.17 & 425 & 150 & 50 & 10300.00 & 44941.00 & 9437.61 & 27048.64 & 13971.17 & 8703.62 \\
\hline & $1200 / 400$ & 33.20 & 346 & 125 & 60 & 12360.00 & 49934.00 & 10486.14 & 28886.82 & 14807.72 & 9489.65 \\
\hline & $1200 / 600$ & 57.24 & 583 & 297 & 30 & 6180.00 & 30486.00 & 7316.64 & 18839.13 & 9770.17 & 6472.23 \\
\hline & $1200 / 600$ & 52.07 & 532 & 272 & 40 & 8240.00 & 35480.00 & 8160.40 & 22343.88 & 11615.69 & 7408.67 \\
\hline & $1200 / 600$ & 45.15 & 464 & 238 & 50 & 10300.00 & 40999.00 & 9019.78 & 24998.32 & 12939.11 & 8214.49 \\
\hline & $1200 / 600$ & 36.58 & 380 & 197 & 60 & 12360.00 & 46518.00 & 10233.96 & 28916.05 & 15008.06 & 9402.76 \\
\hline & $1200 / 800$ & 58.93 & 600 & 403 & 30 & 6180.00 & 26018.00 & 6244.32 & 15774.97 & 8157.92 & 5474.01 \\
\hline & $1200 / 800$ & 54.39 & 555 & 374 & 40 & 8240.00 & 30749.00 & 7379.76 & 19395.85 & 10085.02 & 6590.22 \\
\hline & $1200 / 800$ & 49.51 & 507 & 342 & 50 & 10300.00 & 36268.00 & 7978.96 & 22444.81 & 11642.44 & 7316.23 \\
\hline & $1200 / 800$ & 40.85 & 422 & 286 & 60 & 12360.00 & 42576.00 & 8940.96 & 25014.68 & 12863.84 & 8152.32 \\
\hline
\end{tabular}




\begin{tabular}{|c|c|c|c|c|c|c|c|c|c|c|c|}
\hline \multirow{12}{*}{$\begin{array}{c}100 \times 50 \times 15 \times 0.8 \\
\text { Bare } \\
2000 \mathrm{~mm}\end{array}$} & $1200 / 400$ & 55.22 & 563 & 195 & 30 & 4200.00 & 34691.00 & 8325.84 & 13038.27 & 6023.68 & 5525.23 \\
\hline & $1200 / 400$ & 48.09 & 493 & 172 & 40 & 5600.00 & 38371.00 & 9209.04 & 14608.22 & 6749.00 & 6154.01 \\
\hline & $1200 / 400$ & 37.61 & 390 & 139 & 50 & 7000.00 & 43627.00 & 10034.21 & 16028.56 & 7405.19 & 6730.61 \\
\hline & $1200 / 400$ & 29.19 & 307 & 112 & 60 & 8400.00 & 48095.00 & 10580.90 & 17203.58 & 7948.05 & 7164.66 \\
\hline & $1200 / 600$ & 56.59 & 576 & 293 & 30 & 4200.00 & 31275.00 & 7506.00 & 11790.05 & 5447.00 & 4989.35 \\
\hline & $1200 / 600$ & 50.57 & 517 & 264 & 40 & 5600.00 & 36268.00 & 8341.64 & 13532.32 & 6251.93 & 5641.65 \\
\hline & $1200 / 600$ & 41.20 & 425 & 219 & 50 & 7000.00 & 41524.00 & 9135.28 & 15058.26 & 6956.92 & 6230.84 \\
\hline & $1200 / 600$ & 32.32 & 338 & 176 & 60 & 8400.00 & 46518.00 & 10233.96 & 16377.13 & 7566.23 & 6871.23 \\
\hline & $1200 / 800$ & 58.01 & 590 & 397 & 30 & 4200.00 & 26807.00 & 6433.68 & 10149.67 & 4689.15 & 4286.61 \\
\hline & $1200 / 800$ & 52.80 & 539 & 363 & 40 & 5600.00 & 32852.00 & 7555.96 & 12120.09 & 5599.48 & 5079.58 \\
\hline & $1200 / 800$ & 45.78 & 470 & 318 & 50 & 7000.00 & 38633.00 & 8499.26 & 13767.64 & 6360.65 & 5743.73 \\
\hline & $1200 / 800$ & 36.20 & 376 & 255 & 60 & 8400.00 & 44678.00 & 9382.38 & 15317.85 & 7076.85 & 6367.00 \\
\hline \multirow{12}{*}{$\begin{array}{c}\text { 100x } 50 \times 15 \times 0.8 \\
\text { Restrained } \\
600 \mathrm{~mm}\end{array}$} & $1200 / 400$ & 58.84 & 599 & 206 & 30 & 9000.00 & 31800.00 & 7632.00 & 927583.74 & 31042.55 & 10005.94 \\
\hline & $1200 / 400$ & 53.61 & 547 & 190 & 40 & 12000.00 & 36005.00 & 8281.50 & 1146982.48 & 35218.93 & 11009.09 \\
\hline & $1200 / 400$ & 44.97 & 462 & 162 & 50 & 15000.00 & 42576.00 & 9366.72 & 1364556.54 & 41652.03 & 12624.70 \\
\hline & $1200 / 400$ & 29.68 & 312 & 114 & 65 & 19500.00 & 52037.00 & 10407.40 & 1562541.02 & 50832.53 & 14435.83 \\
\hline & $1200 / 600$ & 58.82 & 598 & 304 & 30 & 9000.00 & 29172.00 & 7001.28 & 879066.13 & 28499.13 & 9181.25 \\
\hline & $1200 / 600$ & 52.15 & 533 & 272 & 40 & 12000.00 & 35480.00 & 8160.40 & 1145755.64 & 34715.75 & 10849.25 \\
\hline & $1200 / 600$ & 40.79 & 421 & 217 & $\begin{array}{l}40 \\
50\end{array}$ & 15000.00 & 43627.00 & 9161.67 & 1371532.54 & 42661.99 & 12524.30 \\
\hline & $1200 / 600$ & 27.69 & 292 & 154 & 65 & 19500.00 & 52562.00 & 10512.40 & 1552303.03 & 51325.24 & 14579.74 \\
\hline & $1200 / 800$ & 57.67 & 587 & 395 & 30 & 9000.00 & 27332.00 & 6559.68 & 869901.03 & 26734.74 & 8605.48 \\
\hline & $1200 / 800$ & 48.80 & 500 & 337 & 40 & 12000.00 & 36794.00 & 8094.68 & 1199153.25 & 36008.62 & 10911.44 \\
\hline & $1200 / 800$ & 38.21 & 396 & 268 & 50 & 15000.00 & 44152.00 & 9271.92 & 1358610.02 & 43154.46 & 12673.13 \\
\hline & $1200 / 800$ & 25.30 & 269 & 184 & 65 & 19500.00 & 53614.00 & 10186.66 & 1550356.04 & 52325.95 & 14346.88 \\
\hline \multirow{12}{*}{$\begin{array}{c}\text { 100x50x15x0.8 } \\
\text { Restrained } \\
3000 \mathrm{~mm}\end{array}$} & $1200 / 400$ & 62.64 & 636 & 218 & 30 & 7350.00 & 20499.00 & 6969.66 & 25933.28 & 11757.98 & 6762.61 \\
\hline & $1200 / 400$ & 53.13 & 542 & 188 & 40 & 9800.00 & 25230.00 & 8578.20 & 37373.20 & 15694.61 & 8581.43 \\
\hline & $1200 / 400$ & 40.83 & 421 & 149 & 50 & 12250.00 & 31275.00 & 9695.25 & 46943.78 & 19576.56 & 10056.18 \\
\hline & $1200 / 400$ & 31.04 & 325 & 118 & 60 & 14700.00 & 36794.00 & 10302.32 & 52821.47 & 22544.85 & 10998.20 \\
\hline & $1200 / 600$ & 63.46 & 644 & 327 & 30 & 7350.00 & 21288.00 & 6173.52 & 24521.65 & 11561.45 & 6229.45 \\
\hline & $1200 / 600$ & 55.11 & 562 & 286 & 40 & 9800.00 & 25230.00 & 7569.00 & 34827.49 & 15159.36 & 7827.65 \\
\hline & $1200 / 600$ & 43.68 & 449 & 231 & 50 & 12250.00 & 31275.00 & 9069.75 & 45301.84 & 19246.96 & 9577.07 \\
\hline & $1200 / 600$ & 33.93 & 354 & 184 & 60 & 14700.00 & 36794.00 & 9934.38 & 50959.69 & 22144.98 & 10674.91 \\
\hline & $1200 / 800$ & 62.53 & 635 & 426 & 30 & 7350.00 & 22339.00 & 5361.36 & 24586.30 & 11791.89 & 5733.76 \\
\hline & $1200 / 800$ & 57.26 & 583 & 392 & 40 & 9800.00 & 24967.00 & 6741.09 & 31211.25 & 14225.58 & 7103.95 \\
\hline & $1200 / 800$ & 47.06 & 483 & 326 & 50 & 12250.00 & 30749.00 & 8302.23 & 42854.88 & 18565.46 & 8931.08 \\
\hline & $1200 / 800$ & 37.63 & 390 & 265 & 60 & 14700.00 & 36794.00 & 9198.50 & 48336.28 & 21543.08 & 10056.93 \\
\hline
\end{tabular}




\begin{tabular}{|c|c|c|c|c|c|c|c|c|c|c|c|}
\hline \multirow{12}{*}{$\begin{array}{c}\text { 100x50x15x1 } \\
\text { Bare } \\
200 \mathrm{~mm}\end{array}$} & $1200 / 400$ & 60.49 & 615 & 212 & 30 & 12300.00 & 38108.00 & 14099.96 & 1114575.16 & 37202.71 & 16060.68 \\
\hline & $1200 / 400$ & 55.88 & 570 & 197 & 40 & 16400.00 & 42838.00 & 15850.06 & 1400087.21 & 41926.16 & 18069.63 \\
\hline & $1200 / 400$ & 48.52 & 497 & 174 & 50 & 20500.00 & 50460.00 & 17661.00 & 1792647.01 & 49471.02 & 20526.54 \\
\hline & $1200 / 400$ & 33.95 & 354 & 128 & 65 & 26650.00 & 62024.00 & 19847.68 & 2081717.71 & 60738.02 & 23755.03 \\
\hline & $1200 / 600$ & 60.36 & 614 & 312 & 30 & 12300.00 & 34691.00 & 13182.58 & 1064243.56 & 33904.86 & 14885.82 \\
\hline & $1200 / 600$ & 53.89 & 550 & 280 & 40 & 16400.00 & 42313.00 & 15232.68 & 1467567.17 & 41463.76 & 17534.68 \\
\hline & $1200 / 600$ & 44.22 & 455 & 234 & 50 & 20500.00 & 51774.00 & 17603.16 & 1821631.95 & 50749.51 & 20656.93 \\
\hline & $1200 / 600$ & 30.91 & 324 & 169 & 65 & 26650.00 & 62812.00 & 20099.84 & 2091350.67 & 61499.32 & 24055.50 \\
\hline & $1200 / 800$ & 59.05 & 601 & 404 & 30 & 12300.00 & 32326.00 & 12283.88 & 1066606.07 & 31644.36 & 13878.62 \\
\hline & $1200 / 800$ & 50.65 & 518 & 349 & 40 & 16400.00 & 43627.00 & 15269.45 & 1574939.06 & 42785.41 & 17748.83 \\
\hline & $1200 / 800$ & 39.48 & 408 & 277 & 50 & 20500.00 & 54402.00 & 17408.64 & 1857801.10 & 53293.22 & 20838.29 \\
\hline & $1200 / 800$ & 28.66 & 302 & 206 & 65 & 26650.00 & 63863.00 & 19797.53 & 2085816.67 & 62502.71 & 23938.35 \\
\hline \multirow{12}{*}{$\begin{array}{c}100 \times 50 \times 15 \times 1 \\
\text { Bare } \\
1000 \mathrm{~mm}\end{array}$} & $1200 / 400$ & 60.75 & 617 & 212 & 30 & 10800.00 & 37845.00 & 14381.10 & 51987.68 & 22682.61 & 13597.16 \\
\hline & $1200 / 400$ & 57.09 & 581 & 201 & 40 & 14400.00 & 41524.00 & 15363.88 & 66481.52 & 26764.01 & 15089.83 \\
\hline & $1200 / 400$ & 53.05 & 542 & 188 & 50 & 18000.00 & 45729.00 & 16462.44 & 70619.29 & 29002.51 & 16237.53 \\
\hline & $1200 / 400$ & 48.37 & 496 & 173 & 60 & 21600.00 & 50460.00 & 17661.00 & 78995.13 & 32200.98 & 17644.96 \\
\hline & $1200 / 600$ & 61.46 & 624 & 317 & 30 & 10800.00 & 33640.00 & 12783.20 & 46376.10 & 20199.04 & 12094.92 \\
\hline & $1200 / 600$ & 57.12 & 582 & 296 & 40 & 14400.00 & 38108.00 & 14481.04 & 56853.33 & 23785.61 & 13907.96 \\
\hline & $1200 / 600$ & 51.29 & 524 & 268 & 50 & 18000.00 & 45466.00 & 15913.10 & 70558.69 & 28900.08 & 15875.35 \\
\hline & $1200 / 600$ & 42.87 & 442 & 227 & 60 & 21600.00 & 53088.00 & 17519.04 & 79844.35 & 33261.46 & 17767.33 \\
\hline & $1200 / 800$ & 61.99 & 630 & 423 & 30 & 10800.00 & 28909.00 & 10985.42 & 40888.89 & 17583.88 & 10446.13 \\
\hline & $1200 / 800$ & 55.42 & 565 & 380 & 40 & 14400.00 & 37319.00 & 13808.03 & 57210.03 & 23589.36 & 13462.07 \\
\hline & $1200 / 800$ & 47.30 & 485 & 327 & 50 & 18000.00 & 47306.00 & 16084.04 & 72543.75 & 29906.62 & 16186.88 \\
\hline & $1200 / 800$ & 39.38 & 407 & 276 & 60 & 21600.00 & 54402.00 & 17408.64 & 79524.84 & 33627.76 & 17767.71 \\
\hline \multirow{12}{*}{$\begin{array}{c}\text { 100x50x15x1 } \\
\text { Bare } \\
1500 \mathrm{~mm}\end{array}$} & $1200 / 400$ & 55.31 & 564 & 195 & 30 & 8850.00 & 43364.00 & 16044.68 & 27850.96 & 14508.72 & 11934.11 \\
\hline & $1200 / 400$ & 49.05 & 502 & 175 & 40 & 11800.00 & 50197.00 & 17568.95 & 32108.01 & 16719.75 & 13390.58 \\
\hline & $1200 / 400$ & 38.96 & 403 & 143 & 50 & 14750.00 & 57819.00 & 19080.27 & 35036.00 & 18116.97 & 14526.93 \\
\hline & $1200 / 400$ & 30.41 & 319 & 116 & 60 & 17700.00 & 64652.00 & 20688.64 & 37450.96 & 19203.29 & 15582.61 \\
\hline & $1200 / 600$ & 56.61 & 577 & 294 & 30 & 8850.00 & 38896.00 & 14391.52 & 24637.12 & 12816.25 & 10625.35 \\
\hline & $1200 / 600$ & 50.98 & 521 & 266 & 40 & 11800.00 & 45729.00 & 16005.15 & 29247.81 & 15230.23 & 12198.20 \\
\hline & $1200 / 600$ & 42.38 & 437 & 225 & 50 & 14750.00 & 53351.00 & 17605.83 & 32619.87 & 16891.11 & 13469.98 \\
\hline & $1200 / 600$ & 33.35 & 348 & 181 & 60 & 17700.00 & 60972.00 & 19511.04 & 35486.92 & 18214.41 & 14735.89 \\
\hline & $1200 / 800$ & 58.03 & 591 & 397 & 30 & 8850.00 & 33903.00 & 12883.14 & 21064.27 & 10932.12 & 9288.12 \\
\hline & $1200 / 800$ & 53.00 & 541 & 364 & 40 & 11800.00 & 40736.00 & 14664.96 & 25893.02 & 13474.67 & 10992.10 \\
\hline & $1200 / 800$ & 46.45 & 477 & 322 & 50 & 14750.00 & 48095.00 & 16352.30 & 29746.76 & 15428.83 & 12412.77 \\
\hline & $1200 / 800$ & 36.78 & 382 & 259 & 60 & 17700.00 & 56505.00 & 18081.60 & 33133.97 & 17032.64 & 13714.84 \\
\hline
\end{tabular}




\begin{tabular}{|c|c|c|c|c|c|c|c|c|c|c|c|}
\hline \multirow{12}{*}{$\begin{array}{c}\text { 100x45x10x0.8 } \\
\text { Bare } \\
200 \mathrm{~mm}\end{array}$} & $1200 / 400$ & 57.90 & 589 & 203 & 30 & 7800.00 & 29961.00 & 6891.03 & 732483.53 & 29111.50 & 9141.78 \\
\hline & $1200 / 400$ & 53.05 & 542 & 188 & 40 & 10400.00 & 33377.00 & 7676.71 & 927276.48 & 32542.79 & 10194.99 \\
\hline & $1200 / 400$ & 46.92 & 481 & 169 & 50 & 13000.00 & 38108.00 & 8383.76 & 1097525.64 & 37188.81 & 11291.22 \\
\hline & $1200 / 400$ & 37.55 & 389 & 139 & 60 & 15600.00 & 43101.00 & 9051.21 & 1217305.85 & 42041.12 & 12363.72 \\
\hline & $1200 / 600$ & 57.85 & 589 & 300 & 30 & 7800.00 & 27595.00 & 6346.85 & 705935.29 & 26846.80 & 8423.19 \\
\hline & $1200 / 600$ & 52.85 & 540 & 275 & 40 & 10400.00 & 31800.00 & 7314.00 & 906948.72 & 31025.53 & 9715.28 \\
\hline & $1200 / 600$ & 43.88 & 451 & 232 & 50 & 13000.00 & 38371.00 & 8057.91 & 1106953.47 & 37447.00 & 11008.66 \\
\hline & $1200 / 600$ & 34.68 & 361 & 188 & 60 & 15600.00 & 43890.00 & 8778.00 & 1224083.32 & 42797.22 & 12169.10 \\
\hline & $1200 / 800$ & 57.70 & 587 & 395 & 30 & 7800.00 & 24967.00 & 5992.08 & 683074.65 & 24333.46 & 7852.01 \\
\hline & $1200 / 800$ & 51.11 & 523 & 352 & 40 & 10400.00 & 31537.00 & 6938.14 & 933709.65 & 30796.78 & 9346.18 \\
\hline & $1200 / 800$ & 40.97 & 423 & 286 & 50 & 13000.00 & 38896.00 & 8168.16 & 1110080.17 & 37949.34 & 11158.38 \\
\hline & $1200 / 800$ & 31.55 & 330 & 225 & 60 & 15600.00 & 45204.00 & 9040.80 & 1234082.76 & 44054.51 & 12531.35 \\
\hline
\end{tabular}

- Units are in $(\mathrm{mm}),(\mathrm{min}),\left({ }^{\circ} \mathrm{C}\right)$, and $(\mathrm{N})$. 


\section{References}

[1] B.W. Schafer, Local, Distortional, and Euler Buckling of Thin-Walled Columns, Journal of Structural Engineering, 128 (2002) 289-299.

[2] AISI, North American Specification for the Design of Cold-Formed Steel Structural Members, American Iron and Steel Institute, Washington DC, 2007.

[3] A. Shahbazian, Y.C. Wang, Calculating the Global Buckling Resistance of Thin-Walled Steel Members with Uniform and Non-Uniform Elevated Temperatures under Axial Compression, ThinWalled Structures, In Press, Corrected Proof, DOI: 10.1016/j.tws.2011.07.001

[4] B.W. Schafer, S. Adany, Buckling Analysis of Cold-Formed Steel Members using CUFSM:

Conventional and Constrained Finite Strip Methods, in: 18th International Specialty Conference on ColdFormed Steel Structures, Florida USA, 2006.

[5] B.W. Schafer, Review: The Direct Strength Method of Cold-Formed Steel Member Design, Journal of Construction Steel Research, 64 (2008) 766 - 778.

[6] M. Feng, Y.C. Wang, Cold-Formed Thin-Walled Steel Structures in Fire, The Structural Engineer, 80 (2002) 26-27.

[7] M. Feng, Y.C. Wang, J.M. Davies, Thermal performance of cold-formed thin-walled steel panel systems in fire, Fire Safety Journal, 38 (2003) 365-394.

[8] M. Feng, Y.C. Wang, J.M. Davies, Structural behaviour of cold-formed thin-walled short steel channel columns at elevated temperatures. Part 2: Design calculations and numerical analysis, ThinWalled Structures, 41 (2003) 571-594.

[9] M. Feng, Y.C. Wang, J.M. Davies, Axial strength of cold-formed thin-walled steel channels under non-uniform temperatures in fire, Fire Safety Journal, 38 (2003) 679-707.

[10] M. Feng, Numerical and Experimental Studies of Cold-formed Thin-walled Steel Studs in Fire, PhD Thesis, in: Science and Engineering, University of Manchester, Manchester, 2003.

[11] M. Feng, Y.C. Wang, J.M. Davies, Structural behaviour of cold-formed thin-walled short steel channel columns at elevated temperatures. Part 1: experiments, Thin-Walled Structures, 41 (2003) 543570.

[12] M. Feng, Y.C. Wang, J.M. Davies, A numerical imperfection sensitivity study of cold-formed thinwalled tubular steel columns at uniform elevated temperatures, Thin-Walled Structures, 42 (2004) 533555.

[13] M. Feng, Y.C. Wang, An experimental study of loaded full-scale cold-formed thin-walled steel structural panels under fire conditions, Fire Safety Journal, 40 (2005) 43-63.

[14] ABAQUS, v6.10 Documentation, Dassault Systèmes Simulia Corp., 2010.

[15] Y.B. Heva, M. Mahen, Local Buckling Tests of Cold-Formed Steel Compression Members at Elevated Temperatures, in: Proceedings 5th International Conference on Thin-Walled Structures, Gold Coast, Australia, 2008, pp. 745-752.

[16] T. Ranawaka, M. Mahendran, Distortional Buckling Tests of Cold-Formed Steel Compression Members at Elevated Temperatures, Journal of Construction Steel Research, 65 (2009) 249-259.

[17] A. Landesmann, D. Camotim, On the Strength and DSM Design of Cold-Formed Steel Columns Failing Distortionaly under Fire Conditions, in: Stability and Ductility of Steel Structures, Rio de Janeiro, Brazil, 2010, pp. 529-536.

[18] CEN, Eurocode 3: Design of Steel Structures - Part 1-2: General Rules - Structural Fire Design, in: EN1993-1-2:2005, European Standard, Brussels, 2005.

[19] B.W. Schafer, Z. Li, C.D. Moen, Computational modeling of cold-formed steel, Thin-Walled Structures, 48 (2010) 752-762.

[20] O. Kaitila, Imperfection sensitivity analysis of lipped channel columns at high temperatures, Journal of Constructional Steel Research, 58 (2002) 333-351. 
[21] B.W. Schafer, Review: The Direct Strength Method of Cold-Formed Steel Member Design, in: Stability and Ductility of Steel Strutcures, Lisbon, Portugal, 2006. 